The Geological Society of America

Special Paper 505

2014

\title{
What caused terrestrial dust loading and climate downturns between A.D. 533 and 540?
}

\author{
Dallas H. Abbott \\ Dee Breger \\ Pierre E. Biscaye \\ Lamont-Doherty Earth Observatory of Columbia University, Palisades, New York 10964, USA \\ John A. Barron \\ U.S. Geological Survey, 345 Middlefield Road, Menlo Park, California 94025, USA \\ Robert A. Juhl \\ Independent researcher, 1-4-1 Rokko Heights, 906 Shinkawa, Chuo-ku, Tokyo 104-0033, Japan \\ Patrick McCafferty \\ Independent researcher, 7 Windsor Avenue North, Belfast BT9 6EL, Northern Ireland
}

\begin{abstract}
Sn-rich particles, Ni-rich particles, and cosmic spherules are found together at four discrete stratigraphic levels within the 362-360 m depth interval of the Greenland Ice Sheet Project 2 (GISP2) ice core $\left(72.6^{\circ} \mathrm{N}, 38.5^{\circ} \mathrm{W}\right.$, elevation: $\left.3203 \mathrm{~m}\right)$. Using a previously derived calendar-year time scale, these particles span a time of increased dust loading of Earth's atmosphere between A.D. 533 and 540. The Sn-rich and Nirich particles contain an average of 10-11 wt $\% \mathrm{C}$. Their high $\mathrm{C}$ contents coupled with local enrichments in the volatile elements $\mathrm{I}, \mathrm{Zn}, \mathrm{Cu}$, and Xe suggest a cometary source for the dust. The late spring timing of extraterrestrial input best matches the Eta Aquarid meteor shower associated with comet 1P/Halley. An increased flux of cometary dust might explain a modest climate downturn in A.D. 533. Both cometary dust and volcanic sulfate probably contributed to the profound global dimming during A.D. 536 and 537 but may be insufficient sources of fine aerosols. We found tropical marine microfossils and aerosol-sized $\mathrm{CaCO}_{3}$ particles at the end A.D. 535-start A.D. 536 level that we attribute to a low-latitude explosion in the ocean. This additional source of dust is probably needed to explain the solar dimming during A.D. 536 and 537. Although there has been no extinction documented at A.D. 536, our results are relevant because mass extinctions may also have multiple drivers. Detailed examinations of fine particles at and near extinction horizons can help to determine the relative contributions of cosmic and volcanic drivers to mass extinctions.
\end{abstract}

\footnotetext{
${ }^{\dagger}$ Also at Micrographic Arts, P.O. Box 3088, Saratoga Springs, New York 12866, USA.

Abbott, D.H., Breger, D., Biscaye, P.E., Barron, J.A., Juhl, R.A., and McCafferty, P., 2014, What caused terrestrial dust loading and climate downturns between A.D. 533 and 540?, in Keller, G., and Kerr, A.C., eds., Volcanism, Impacts, and Mass Extinctions: Causes and Effects: Geological Society of America Special Paper 505, p. 1-XXX, doi:10.1130/2014.2505(23). For permission to copy, contact editing @ geosociety.org. @ 2014 The Geological Society of America. All rights reserved.
} 


\section{INTRODUCTION}

We have previously used historical, particle, and ion data to propose a calendar-year time scale for the Greenland Ice Sheet Project 2 (GISP2) ice core from central Greenland at depths between $362 \mathrm{~m}$ and $360 \mathrm{~m}$ during part of the early sixth century A.D. Because previous work suggested a significant extraterrestrial influence on climate and tree rings between ca. A.D 533 and 541 (Baillie, 1999, 2007), we selected ice-core samples that covered this time. We found Ni-rich particles and I-type (Fe-oxide) cosmic spherules from 361.8 to $360.51 \mathrm{~m}$ depth, dated by us to between 533 and 540 A.D., the same time range as observations of increased atmospheric dust i.e., "dancing stars," in historical records (Abbott et al., this volume, Chapter 22). There are at least five possible sources for the dust in our samples: asteroidal debris, cometary dust, volcanic sulfates, windblown particles, and terrestrial impact ejecta. In this paper, we address the multiple origins of this dust and its possible effects on climate from 533 to 540 A.D.

\section{Previous Work on Extraterrestrial Debris within Polar Ice}

There are many accepted tracers for extraterrestrial debris in polar ice: noble gas abundances and isotopic compositions (Brook et al., 2000; Lal and Jull, 2005; McGee and Mukhopadhyay, 2013), Ir, Pt, and Ni abundances (Brocas and Picciotto, 1967; Karner et al., 2003; Gabrielli et al., 2004), nonvolcanic Feand Ni-rich spherules (Hodge and Wright, 1964; Hodge et al., 1964; Taylor et al., 1998, 2000), meteoritic fragments (Yada et al., 2004; Misawa et al., 2010), and magnetic properties (Lanci and Kent, 2006). A major drawback to most of these tracers is that they require relatively large volumes and stratigraphic thicknesses of ice. For example, a study of extraterrestrial $\mathrm{He}^{3}$ abundance in replicate samples found that around $1000 \mathrm{~g}$ of ice were needed to achieve reproducible results with $2 \sigma$ errors on the order of $\pm 30 \%$ (Brook et al., 2009). Another study achieved lower errors, but individual samples represented over $100 \mathrm{yr}$ of ice accumulation (Winckler and Fischer, 2006). In addition, noble gases are lost from larger or higher-velocity particles as they heat up during atmospheric entry (Farley et al., 1997; Mukhopadhyay and Farley, 2006). Thus, noble gases can only provide a lower bound on the deposition rate of extraterrestrial debris (Marcantonio et al., 1996, 1998, 1999).

One study of Ir and Pt abundances required 1000-2000 g samples to achieve reproducible results (Karner et al., 2003). Magnetic studies use smaller $360 \mathrm{~g}$ samples but constrain only the background levels of meteoritic smoke recorded in particles 7-17 nanometers in diameter (Lanci and Kent, 2006). In our study, we assessed the composition and origin of particles from a relatively small amount of ice meltwater, between 27 and $102 \mathrm{~g} \mathrm{(mL)} \mathrm{per} \mathrm{sample} \mathrm{(Appendix} \mathrm{Table} \mathrm{1A).} \mathrm{Individual} \mathrm{samples}$ of meltwater represent between 0.3 and $0.92 \mathrm{yr}$ of time. Based on previous ice-core research, such brief intervals of time and masses of ice would be expected to yield no micrometer-sized extraterrestrial particles. As we have shown (Abbott et al., this volume, Chapter 22) and will further demonstrate in this paper, we instead found surprisingly large abundances and sizes of inferred extraterrestrial particles within a restricted stratigraphic interval. These results could mean that the time between A.D. 533 and 540 had an unusually high deposition rate of extraterrestrial particles. In this paper, we make a case for a cometary origin of many of these particles.

\section{COMETS OR ASTEROIDS AS SOURCES OF EXTRATERRESTRIAL DUST IN THE GISP2 ICE CORE}

Our previous findings of Ni-rich particles and cosmic spherules do not require a cometary source for the historically documented dust loading of Earth's atmosphere, i.e., "the dancing stars," between A.D. 533 and 540 (Abbott et al., this volume, Chapter 22). Ni-rich particles and cosmic spherules could come from either asteroids or comets. They are both sources of micrometer-sized cosmic dust particles and interplanetary dust particles (IDPs).

Asteroids are composed of material that was differentiated at the same temperatures as igneous rocks, that is, at minimum primitive liquidus temperatures of $\sim 1100{ }^{\circ} \mathrm{C}$ (McKenzie and Bickle, 1988). Because comets represent material that condensed from the primordial solar nebula at lower temperatures than asteroids, comets should contain higher concentrations of material with low-equilibrium nebular condensation temperatures, in particular C (Table 1; Lodders, 2003). Some ultravolatile materials, for example, water ice and noble gases, are likely to be very rare or absent in asteroids and relatively abundant in comets.

Some cosmic dust contains concentrations of volatile elements such as Sn, Zn, and Bi (Table 2). During the 1990s, all or most of the volatile elements in cosmic dust particles were considered to be volcanogenic contaminants that condensed onto the particle surfaces after they entered Earth's atmosphere (Jessberger et al., 1992; Rietmeijer, 1993, 1995). The most recent research suggests that these volatile elements are integral parts of the grains (e.g., cometary) rather than volcanogenic surface precipitates (Flynn et al., 2006). In the late 1990s, ultra-carbonrich micrometeorites were found in Antarctica (Engrand and Maurette, 1998). As a result of this and other discoveries, the percentage of cosmic dust consisting of carbonaceous chondritelike material has been steadily revised upward. At present, it is estimated that comets (e.g., carbonaceous chondrite-like dust) probably represent the ultimate source of over $80 \%$ of the cosmic dust entering Earth's atmosphere (Engrand, 2011).

\section{Observational Evidence for Excess Concentrations of Volatile Elements in Comets}

Several types of observations constrain the concentrations of volatile elements in comets relative to ordinary chondritic meteorites. The first are direct observations of the coma of comets. The 
What caused terrestrial dust loading and climate downturns between A.D. 533 and 540 ?

TABLE 1. ELEMENTS WITH LOW NEBULAR CONDENSATION TEMPERATURES (DATA FROM LODDERS, 2003)

\begin{tabular}{lcc}
\hline \hline Element & $50 \%$ condensation temperature $\left({ }^{\circ} \mathrm{K}\right)$ & Phase \\
\hline $\mathrm{C}$ & 40 & $\mathrm{CH}_{4} \cdot 7 \mathrm{H}_{2} \mathrm{O}$ plus $\mathrm{CH}_{4}$ (ice) \\
$\mathrm{Xe}$ & 68 & Water \\
$\mathrm{I}$ & 535 & $\mathrm{Cl}$ apatite \\
$\mathrm{Sn}$ & 704 & Fe alloy \\
$\mathrm{Zn}$ & 726 & Forsterite plus enstatite \\
$\mathrm{Pb}$ & 727 & $\mathrm{Fe}$ alloy \\
$\mathrm{Bi}$ & 746 & $\mathrm{Fe}$ alloy \\
$\mathrm{K}$ & 1006 & Feldspar \\
$\mathrm{Cu}$ & 1037 & Fe alloy \\
\hline
\end{tabular}

spectra of comet Ikeyi Seki indicate excess Cu (Rietmeijer, 1988); the spectra from Comet 1P/Halley indicate excess Zn (Krueger and Kissel, 1987). The second are observations of the volatile content of chondritic, porous, cosmic dust, the type of cosmic dust that comes from comets (Bradley and Brownlee, 1986; Brownlee, 1987; Bradley et al., 1999). Chondritic, porous, cosmic dust includes particles with excess $\mathrm{Bi}, \mathrm{Sn}$, and $\mathrm{Zn}$ relative to chondritic meteorites (Rietmeijer, 1989; Schulze et al., 1997; Ciucci et al., 2010). The third are observations of high concentrations of volatiles in the lunar soil. Excess $\mathrm{Zn}$ and $\mathrm{Pb}$ are attributed to input from comets (Dikov et al., 1998). When these concentrations are normalized relative to the concentrations of the same element in chondritic meteorites (e.g., asteroids), they provide an index that can be used to distinguish cometary from asteroidal material.

The volatile elements most diagnostic of a cometary origin are those for which concentrations are highest relative to ordinary chondritic meteorites. The excess concentrations of volatiles can be very high, typically several times chondritic for Sn, but possibly up to 350,000 times chondritic for the same element in cometary dust in an ice core (Table 1; La Violette, 1987). Zn also has very high excess concentrations: $3-4$ times chondritic to possibly 610 times chondritic in material from the 1908 explosion over Tunguska in Siberia. Thus, $\mathrm{Sn}$ and $\mathrm{Zn}$ are good proxies to use to distinguish between cometary and asteroidal material.

\section{LABORATORY METHODS}

Our ice-core samples were processed under a laminar-flow hood. The hood has a filter and positive pressure that prevent con- tamination from local dust. The outside surface of each ice-core sample was rinsed with quartz-distilled water to remove contamination from drilling and atmospheric dust. The remaining ice was melted under the laminar-flow hood and centrifuged. The supernatant was analyzed for ion concentrations using ion chromatography. All of the remaining particle-rich water was placed inside cleaned Teflon washers, glued to cleaned glass slides, and left to evaporate in the laminar-flow hood. All final cleaning and rinsing was done with quartz-distilled water. Each slide was then covered until immediately before insertion into a Zeiss Supra 50 scanning electron microscope (SEM) with attached EDAX energydispersive X-ray spectrometer (EDS). Micrographs were collected in secondary electron (SE), backscattered electron (BSE), or mixed SE and BSE modes. Imaging and analyses were conducted in high-vacuum mode at $15 \mathrm{kV}$ accelerating voltage. In between SEM sessions, each slide was re-covered immediately upon removal from the SEM and stored inside the laminar-flow hood to prevent contamination from atmospheric dust. Marinesediment cores are stored in a different building, thus precluding them as a source of contamination.

Our standard method of searching for interesting particles on the SEM combines 50\% backscattered and 50\% secondary electrons to make a composite image in order to maximize both structural and chemical data. We survey for interesting particles at a magnification of $200 \times$, increasing the magnification when we find an interesting particle or particle group. We select particles that have one or more of the following attributes: distinct sharp edges, a spherical morphology, a biological morphology, or a bright appearance. Each slide of particles from a given

TABLE 2. VOLATILE ELEMENTS AND THEIR ENRICHMENTS IN COMETS AND COMETARY MATERIAL

\begin{tabular}{llll}
\hline \hline Metal & Where observed & Amount & Reference \\
\hline $\mathrm{Bi}$ & Chondritic porous IDP & $4-35$ times chondritic (best 20 times) & Rietmeijer (1989) \\
$\mathrm{Cu}$ & Comet lkeya Seki & high & Rietmeijer (1988) \\
$\mathrm{Pb}$ & Lunar soil & $0.1-0.2$ at\% & Dikov et al. (1998) \\
$\mathrm{Sn}$ & Chondritic aggregate IDP & 3 grains of Sn oxide & Ciucci et al. (2010) \\
$\mathrm{Sn}$ & Chondritic porous IDP & $3-8$ times chondritic (best 6.3 times), includes Sn-rich particles & Rietmeijer (1989) \\
$\mathrm{Sn}$ & Cometary dust in ice core & 350,000 times chondritic? & La Violette (1987) \\
$\mathrm{Sn}$ & Tunguska (comet) & 11.6 times chondritic? & La Violette (1987) \\
$\mathrm{Zn}$ & Lunar soil & 4 at\% & Dikov et al. (1998) \\
$\mathrm{Zn}$ & Dust from comet 1P/Halley & $3-4$ times chondritic & Schulze et al. (1997) \\
$\mathrm{Zn}$ & Comet 1P/Halley & high & Krueger and Kissel (1987) \\
$\mathrm{Zn}$ & Tunguska (comet) & 610 times chondritic & La Violette (1987) \\
\hline Note: IDP-interplanetary dust particle. & & \\
\hline
\end{tabular}


stratigraphic level contains hundreds to thousands of grains; we cannot analyze every grain. The most carbon-rich or fluffy grains are usually not selected. This means that most of our particles are in one or more of the following classes: metal-rich, minerals, biological skeletons, spherules, or glass.

\section{A COMETARY SOURCE FOR Ni-RICH AND Sn-RICH PARTICLES}

Particles of cometary origin typically contain at least a few percent carbon $(\mathrm{C})$. The most primitive asteroids are those most like comets, i.e., carbonaceous chondrites. Although the amount of carbon is quite variable, the most primitive carbonaceous chondrites (CI chondrites) contain $\sim 4 \%$ carbon (Alexander et al., 2012; Marty, 2012). The more primitive chondritic IDPs contain $\sim 12 \%$ carbon (Thomas et al., 1993). Dust from comet 1P/Halley contains $\sim 18 \%$ carbon (Delsemme, 1991; Marty et al., 2013).

Because we coat our samples with $\mathrm{Au} / \mathrm{Pd}$, our semiquantitative X-ray microanalyses are a rough measure of the carbon content of our samples. We use the measured $\mathrm{C}$ content of terrestrial $\mathrm{SiO}_{2}$ grains in our samples to estimate background $\mathrm{C}$ levels (the maximum level of $\mathrm{C}$ potentially attributable to terrestrial sources) of 2-3 wt $\%$ (Appendix Table 1B). On average, we find $~ 11 \mathrm{wt} \%$ $\mathrm{C}$ (range 5-19 wt\%) in our samples of Ni-rich particles (Table 3). This $\mathrm{C}$ content is in the right range for cometary materials but is somewhat low. (We attribute this to our criteria for sample selection, which systematically avoids the most C-rich particles.) We also find local enrichments of the volatile elements $\mathrm{Zn}$ and $\mathrm{Cu}$.

Because the brightness in backscatter mode of $\mathrm{C}$ is directly proportional to its average atomic weight, a particle of nearly pure $\mathrm{C}$ appears dark gray. In contrast, a pure heavy metal oxide or native heavy metal appears light gray or bright white, respectively. With the exception of a grain of native $\mathrm{Ni}$, our Ni-rich samples did not appear as bright in backscatter mode (fig. 3 in Abbott et al., this volume, Chapter 22) as is typical of pure Fe-Ni oxides or pure Fe-Ni metal. The lower relative brightness of our
Ni-rich particles in backscatter mode is consistent with the presence of significant amounts of carbon ( $10 \%$ level) with the metal.

\section{Sn-Rich Particles in the GISP2 Ice Core}

We found small Sn-rich particles at four different horizons in the GISP2 ice core (Figs. 1 and 2; Table 4). Because Sn is a heavy metal, small, Sn-rich particles appear bright in backscatter mode on the SEM. Their relative brightness enhances the visibility of small, Sn-rich particles.

The Sn-rich particles have several characteristics. The first is their small size (Fig. 1). The largest particle is $\sim 3 \mu \mathrm{m}$ in diameter. The particles are platy in appearance. The brightness and compositions of the particles are heterogeneous (Fig. 1; Table 4). The Sn-rich particles all contain substantial C, on average $10 \mathrm{wt} \%$. The Sn-rich particles contain Fe with the Sn or in neighboring grains. Two spectra of Sn-rich particles are best fit with the addition of about $1 \mathrm{wt} \%$ of the noble gas Xe. To achieve a best fit, a third spectrum required the addition of $3.2 \mathrm{wt} \% \mathrm{I}$ in addition to $3.5 \mathrm{wt} \% \mathrm{Xe}$ (Fig. 2). A few of the spectra show significant peaks $(>1 \%)$ in either $\mathrm{Cu}$ or $\mathrm{Zn}$.

The Sn-rich particles show several similarities to other particles of inferred cometary origin. The first is their platy appearance, which resembles that of two Sn-rich particles previously found in cometary-type IDPs (Rietmeijer, 1989; Ciucci et al., 2010). The second similarity is their average $10 \mathrm{wt} \% \mathrm{C}$ content (Delsemme, 1991; Marty et al., 2013), which is closer to that of cometary IDPs $(12 \mathrm{wt} \% \mathrm{C}$ ) than to carbonaceous chondrite meteorites (4 wt\% C). The Fe associated with the $\mathrm{Sn}$ is consistent with models of primordial condensation from the solar nebula (Lodders, 2003), which predict that $\mathrm{Sn}$ (and $\mathrm{Cu}$ ) should initially condense within an iron alloy (Table 1). The last and perhaps most compelling factor is the need to frequently add $\mathrm{Xe}$ and in one case I to fit the spectra of the Sn-rich particles (Fig. 2). (We have carefully checked for sum and escape peaks of $\mathrm{Sn}, \mathrm{O}, \mathrm{C}$, and $\mathrm{Si}$ and found that these are not present at the right energy levels to fit the spectra

TABLE 3. SEMIQUANTITATIVE EDS ANALYSES OF Ni-RICH PARTICLES

\begin{tabular}{|c|c|c|c|c|c|c|c|c|}
\hline Sample no. & $\begin{array}{c}\mathrm{C} \\
\text { (wt \%) }\end{array}$ & $\begin{array}{c}\mathrm{Si} \\
(w \mathrm{t} \%)\end{array}$ & $\begin{array}{c}\mathrm{Ca} \\
\text { (wt\%) }\end{array}$ & $\begin{array}{c}\mathrm{Cr} \\
(\mathrm{wt} \%)\end{array}$ & $\begin{array}{c}\mathrm{Fe} \\
(\mathrm{wt} \%)\end{array}$ & $\begin{array}{c}\mathrm{Ni} \\
\text { (wt\%) }\end{array}$ & $\begin{array}{c}\mathrm{Zn} \\
(\mathrm{wt} \%)\end{array}$ & $\begin{array}{c}\mathrm{Cu} \\
(\mathrm{wt} \%)\end{array}$ \\
\hline $11-8 a$ & 8.8 & 1.1 & 0.3 & 0 & 24.9 & 25.9 & 0 & 0 \\
\hline $11-15 c$ & 10.9 & 1.7 & 0.8 & 0.2 & 34 & 34.9 & 0 & 0 \\
\hline $8-8 a$ & 5.1 & 15.1 & 1.8 & 0.4 & 0.4 & 3 & 14.9 & 36.6 \\
\hline $8-8 b$ & 5.4 & 12.8 & 1.4 & 0.4 & 0.5 & 5.5 & 15 & 37.6 \\
\hline $8-8 c$ & 6.4 & 17.6 & 2.3 & 0.4 & 0.4 & 3.1 & 12.2 & 33.4 \\
\hline $6-20 a$ & 18.4 & 3.6 & 0.1 & 0 & 0 & 65.4 & 0 & 0 \\
\hline $6-20 b$ & 10.9 & 1.2 & 0.4 & 0.1 & 0.2 & 80 & 0.4 & 0 \\
\hline $5 C-9$ & 19.2 & 29.2 & 2.7 & 0.2 & 8.6 & 7.3 & 0 & 0 \\
\hline
\end{tabular}

Note: Sample no._stratigraphic level is the number before the dash; the number after the dash is the grain number within a given stratigraphic level. Suffixes of a, b, and c represent multiple analyses of the same grain. Differences of a few percent between analyses of the same grain primarily reflect local heterogeneity rather than analytical error. None of these samples contained more than 1 wt\% Ti, which would be present in terrestrial material (Hodge and Wright, 1964). Sample 11-8 in Figures 3A and 3B (Abbott et al., this volume, Chapter 22), micrograph (85\% backscattered electrons [BSE]), 15\% in-lens secondary electrons (ILSE). Sample $8-8$ in Figure 11 micrograph (50\% BSE, 50\% ILSE). This might be a refractory grain like that found by Wark (1986). Sample 6-20 in Figures 3C and 3D (Abbott et al., this volume, Chapter 22), micrograph 50\% BSE, 50\% SE2 (secondary electrons). Sample 5C-9 in Figures 3E and 3F (Abbott et al., this volume, Chapter 22 ) micrograph 50\% BSE, 50\% ILSE. 

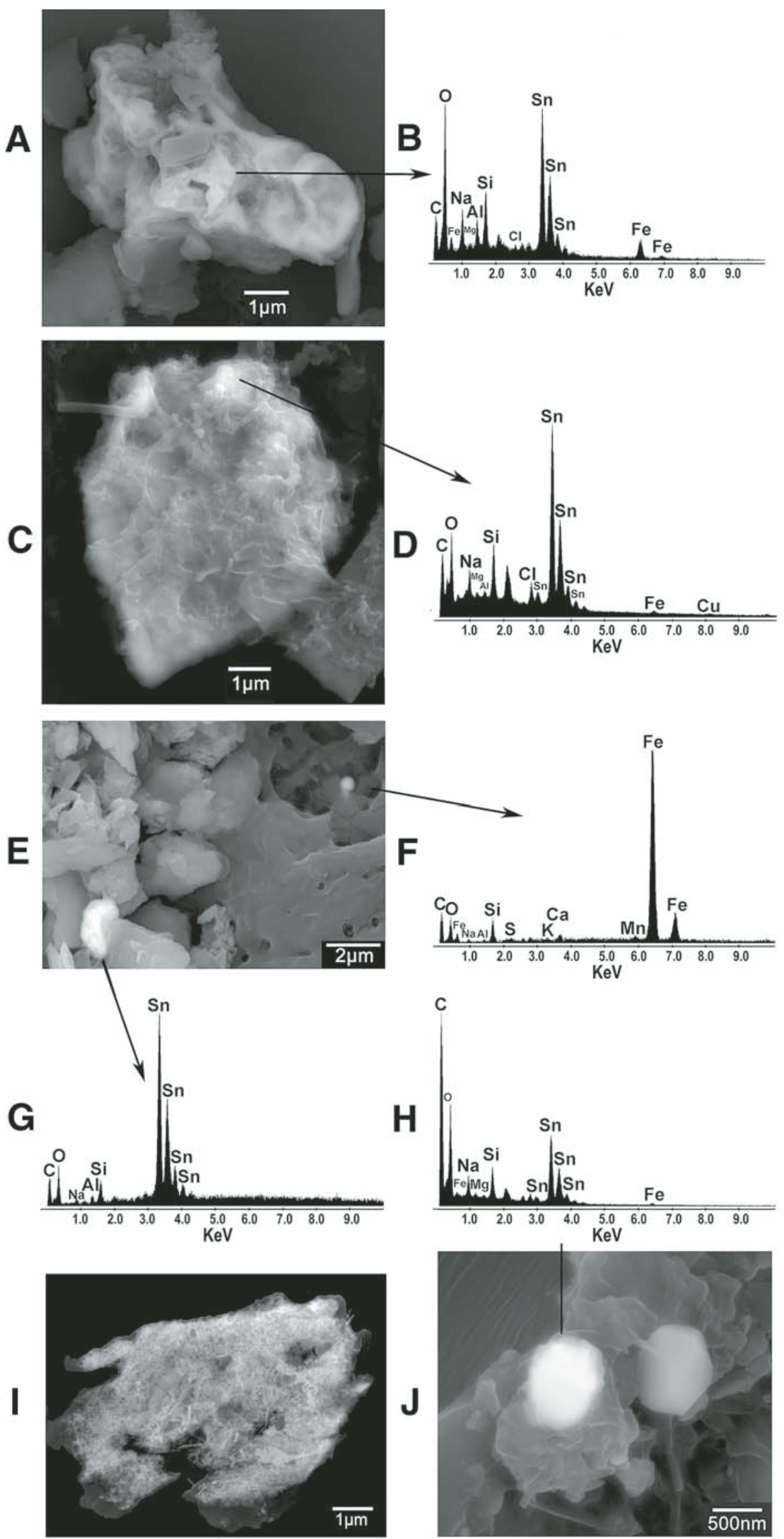

Figure 1. Scanning electron microscope (SEM) micrographs of particles from the ice core. (A, C, E, J) Sn-rich particles with one $\mathrm{Fe}$-rich spherule in E. (B, D, F, G, H) Semiquantitative energy-dispersive $\mathrm{X}$-ray microanalyses of compositions. (Note that the peak heights are not absolute so no scale is given for peak heights. This means that the relative heights of nearby spectral peaks provide a good estimate of relative abundances of these elements. In contrast, the relative heights of peaks with different energies are only loosely correlated to their relative abundance.) Four out of five analyses are of Sn-rich particles. Analysis D shows a small but distinct $\mathrm{Cu}$ peak in addition to $\mathrm{Sn}$ peaks. The remaining analysis is of a Fe-rich spherule (F). (I) Ni-rich particle-analysis in Table 3. Ratios of backscattered and secondary electrons were adjusted to maximum the image quality: (A) $100 \%$ BSE (backscattered electron mode); (C, I) 50\% BSE, 50\% ILSE (in-lens secondary electron mode); (E) $90 \%$ BSE, 10\% ILSE, (J) 50\% BSE, 50\% SE2 (standard secondary electron mode). Black arrows or lines point from particles to their spectra. 

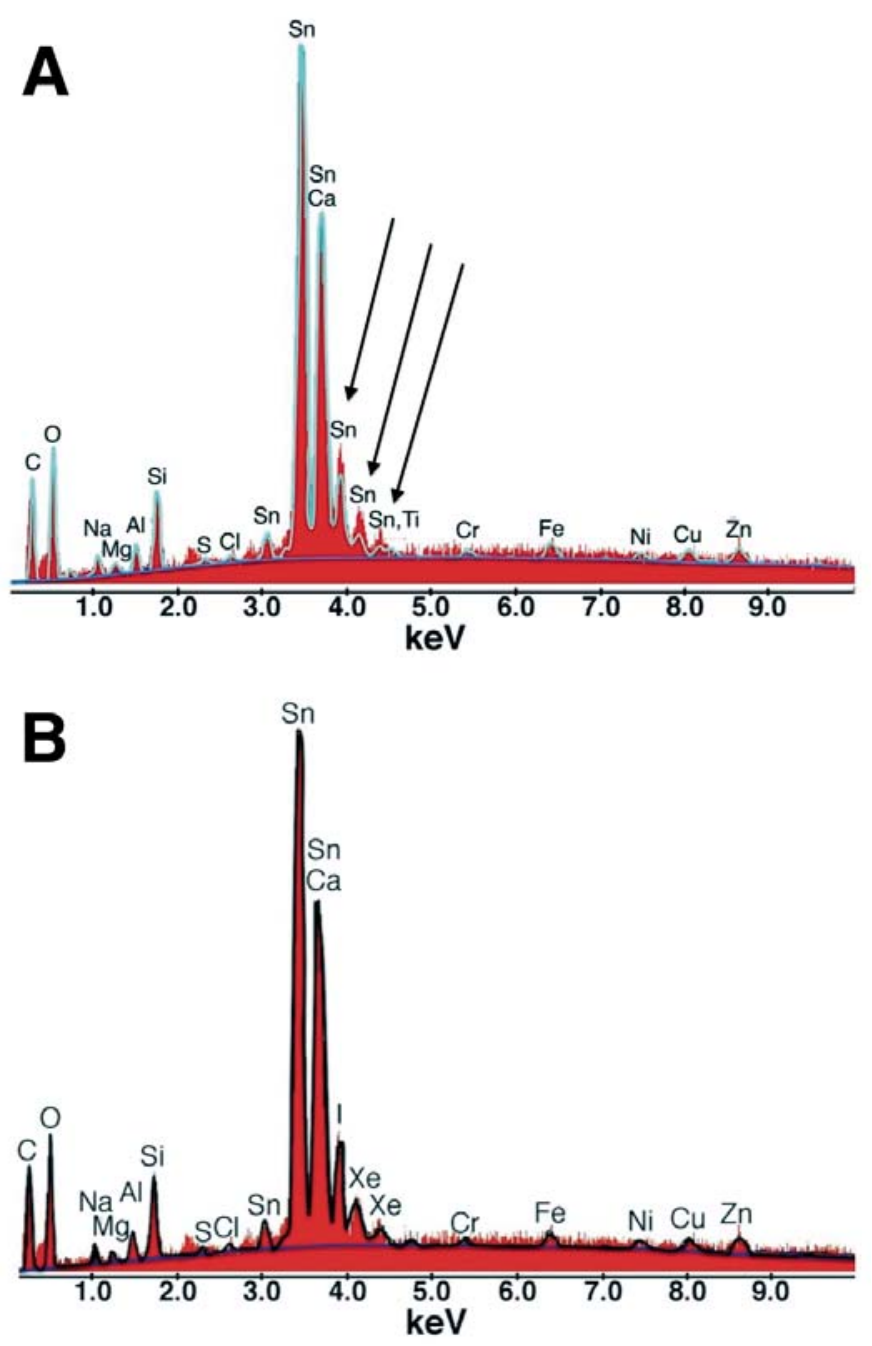

without the addition of Xe and I. No rare earth elements fit the spectra.) Xe and I are both highly volatile elements with nebular condensation temperatures of $68 \mathrm{~K}$ and $535 \mathrm{~K}$, respectively (Table 1). Xe is thought to condense with water in the solar nebula (Lodders, 2003). In addition, some Xe isotopes can be produced during bombardment of iodine by subatomic particles in the solar wind (Pepin et al., 1995). The Sn-rich particles sometimes contain
Figure 2. Comparison of two models for the composition of Sn-rich particle. (Note that the peak heights are not absolute so no scale is given for peak heights. This means that the relative heights of nearby spectral peaks provide a good estimate of relative abundances of these elements. In contrast, the relative heights of peaks with different energies are only loosely correlated to their relative abundance.) Spectral peaks from the $\mathrm{Au} / \mathrm{Pd}$ coating are not included in either model. (Micrograph of particle is given in Figure 1E; spectrum is in Fig. 1G.) Red area-raw spectrum. Dark blue line-background to the spectrum. (A) Light-blue line-model of the spectral peaks based on selected element peak locations and the accelerating voltage used for the analysis. Red area extends above the light-blue line to the right of the peak labeled $\mathrm{Sn}, \mathrm{Ca}$. The data are poorly fit here at the three peaks designated by arrows. (B) Black line-model of spectral peaks The spectrum is best fit by adding both $\mathrm{Xe}$ and I to the Sn and Ca peaks between 3.8 and $4.8 \mathrm{keV}$. $\mathrm{Cu}, \mathrm{Zn}, \mathrm{Ni}$, and $\mathrm{Fe}$ are also present at modest levels.

significant $\mathrm{Zn}$ and $\mathrm{Cu}$, i.e., two other volatile elements that are enriched in comets relative to asteroids. Thus, the overall patterns of morphology and elemental abundance of the Sn-rich particles are most consistent with a cometary source.

The final argument for a cometary origin of the Sn particles is their co-occurrence with the Ni-rich particles (Fig. 3). The Nirich particles, more generally accepted as extraterrestrial, also have high $\mathrm{C}$ contents that resemble the $\mathrm{C}$ contents of cometary dust (Table 3). Thus, if the high $\mathrm{C}$ contents of the Ni-rich particles are accepted as being indicative of cometary origin, it follows that the four co-occurrences of high-C, Sn-rich particles are also likely to have a cometary origin.

\section{POTENTIAL SOURCES OF COMETARY DEBRIS}

Now that we have made a case for a cometary source of the Sn-rich and Ni-rich dust in our samples, we seek to determine whether or not a specific comet or comets can be linked to this dust. We use two data sets to provide constraints: the changes in volume of extraterrestrial debris over time, and the seasonality of input of extraterrestrial debris. Finally, we use modeling of cometary orbits to determine those comets that could have shed debris that would affect Earth during its rotation about the Sun.

In the $10 \mathrm{yr}$ period between A.D. 532 and 542 covered by our ice-core samples, there were seven observed comets (Hasegawa,

TABLE 4. SEMIQUANTITATIVE MICROANALYSES OF Sn-RICH PARTICLES

\begin{tabular}{|c|c|c|c|c|c|c|c|c|c|c|c|c|c|}
\hline $\begin{array}{l}\text { Sample } \\
\text { no. }\end{array}$ & $\begin{array}{c}\mathrm{C} \\
(w t \%)\end{array}$ & $\begin{array}{c}\mathrm{O} \\
(w t \%)\end{array}$ & $\begin{array}{c}\mathrm{Na} \\
(\mathrm{wt} \%)\end{array}$ & $\begin{array}{c}\mathrm{Al} \\
(\mathrm{wt} \%)\end{array}$ & $\begin{array}{c}\mathrm{Si} \\
(\mathrm{wt} \%)\end{array}$ & $\begin{array}{c}\mathrm{Sn} \\
(\mathrm{wt} \%)\end{array}$ & $\begin{array}{c}\mathrm{Ca} \\
(\mathrm{wt} \%)\end{array}$ & $\begin{array}{c}\mathrm{Cr} \\
\text { (wt\%) }\end{array}$ & $\begin{array}{c}\mathrm{Fe} \\
(\mathrm{wt} \%)\end{array}$ & $\begin{array}{c}\mathrm{Ni} \\
\text { (wt\%) }\end{array}$ & $\begin{array}{c}\mathrm{Zn} \\
(\mathrm{wt} \%)\end{array}$ & $\begin{array}{c}\mathrm{Cu} \\
(\mathrm{wt} \%)\end{array}$ & Other elements \\
\hline $11-57 a$ & 5.1 & 24.4 & 4.1 & 1.7 & 3.7 & 47.2 & 1.9 & 0.2 & 5.7 & 0.6 & 2.2 & 0.7 & $0.8 \% \mathrm{Xe}$ \\
\hline $11-57 b$ & 5.3 & 38 & 6.4 & 2.2 & 11.4 & 22.7 & 1.7 & 0 & 9 & 0 & 0.4 & 0 & $0.7 \% \mathrm{Xe}$ \\
\hline $11-57 c$ & 5.9 & 23.9 & 4.2 & 1.7 & 3.8 & 45.9 & 2.1 & 0 & 8.3 & 0.3 & 1.7 & 0.4 & $0.7 \% \mathrm{Xe}$ \\
\hline $6-1 b$ & 32.3 & 23.8 & 2.8 & 0.2 & 3.1 & 33.1 & 1.6 & 0 & 1.2 & 0.1 & 0.7 & 0.4 & No Xe \\
\hline $5 C-8 a$ & 4 & 6.2 & 0.7 & 0.7 & 1.8 & 59 & 3.5 & 0.8 & 2.48 & 2.1 & 7 & 4.3 & $3.2 \% \mathrm{I}, 3.5 \% \mathrm{Xe}$ \\
\hline $4 A-30 a$ & 6.8 & 13.1 & 2.9 & 0.3 & 2.1 & 68.9 & 1.3 & 0 & 0.7 & 0.4 & 0.4 & 0.4 & $1.2 \% \mathrm{Xe}$ \\
\hline $4 A-30 b$ & 7.4 & 14.8 & 3.4 & 0.5 & 4.1 & 63.9 & 1.4 & 0 & 0.9 & 0.4 & 0 & 0.9 & $0.8 \% \mathrm{Xe}$ \\
\hline $4 A-30 c$ & 11 & 20.4 & 5.2 & 0.5 & 6.7 & 52 & 1.4 & 0 & 0.3 & 0 & 0.2 & 0 & $0.7 \% \mathrm{Xe}$ \\
\hline
\end{tabular}

Note: Differences above the percent level reflect sample heterogeneity. Sample 11-57 is Figures $1 \mathrm{~A}$ and $1 \mathrm{~B}$; sample $5 \mathrm{C}-8$ is Figures $1 \mathrm{E}$ and $1 \mathrm{G}$; sample $4 \mathrm{~A}-30$ is Figures $1 \mathrm{C}$ and $1 \mathrm{D}$; sample $6-1 \mathrm{~b}$ is Figures $1 \mathrm{H}$ and $1 \mathrm{~J}$. 
1980; Kronk, 1984). In comparison, there were seven comet passes observed between A.D. 500 and 532 (a 32 yr period) and five comet passes between A.D. 542 and 560 (a 28 yr period). It is possible that one or more of the debris fields left behind by comets (i.e., the sources of meteor showers) might have been strengthened prior to A.D. 533. If more than one meteor shower was strengthened, the volumes of extraterrestrial debris would not decrease uniformly over time but would show multiple peaks and lows. If only one meteor shower was strengthened, the volume of extraterrestrial debris should decrease relatively uniformly over time.

The change in volume of extraterrestrial material over time (Fig. 4) is derived from summing the estimated volumes of Nirich particles, Sn-rich particles, and I-type cosmic spherules in each sample that contains them. The upper envelope of volumes (four samples) shows a linear power of 2 decline from A.D. 533 to 540 .

\section{Discussion}

The volume of extraterrestrial dust from A.D. 533 to 540 measured in our GISP2 samples declines over time. The first and simplest interpretation is that dust from a single comet pass produced declining volumes of cosmic dust starting in A.D. 533 and ending in A.D. 540. The data also permit a second interpretation involving multiple injections of cosmic dust. The volume of cosmic dust is greatest in A.D. 533 and declines until A.D. 536. Later in A.D. 536, there is a new injection of cosmic dust that declines until A.D. 537. There is a final injection of cosmic dust in A.D. 538 that declines until A.D. 539-540. With our data set, we cannot distinguish among these interpretations.

There are other caveats. Our ice samples are small, far smaller than is necessary to obtain good constraints on the size

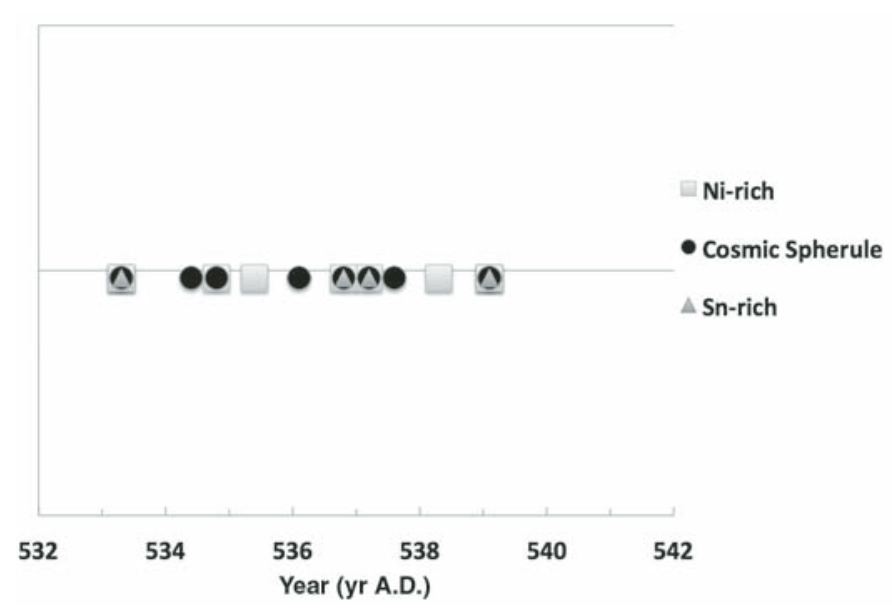

Figure 3. Extraterrestrial material versus calendar-year age in the Greenland Ice Sheet Project 2 (GISP2) ice core. Gray squares with black rim-Ni-rich particles; solid black circles-I-type cosmic spherules; gray triangles with black rim-Sn-rich particles. distribution of extraterrestrial particles (Peucker-Ehrenbrink and Ravizza, 2000). Our methods do not allow us to constrain the abundance of nanometer-sized extraterrestrial particles. The latter are fine aerosol sized, the most likely particles to remain in the atmosphere for months at a time and to reduce the transparency of the atmosphere during their residence. Thus, we do not know if a reduced or increased volume of fine-aerosol-sized particles accompanied the apparently reduced volume of larger extraterrestrial particles during A.D. 536 and 537.

\section{Seasonality of Cosmic Input}

Although ice-core records usually have some uncertainty as to their absolute age, the seasons within annual ice-core records are relatively well defined. The GISP2 ice core shows seasonal changes in bubble and near-surface grain structure, $\delta^{18} \mathrm{O}$, and conductivity that allow identification of annual layers (Alley et al., 1997; Meese et al., 1997). Within the Holocene, the counting of annual layers is reproducible at the $1 \%$ level. This means that it is possible to estimate the seasonality of input of extraterrestrial debris into the GISP2 ice core.

If the debris can be related to a specific season and meteor shower, we have a stronger basis for relating it to a specific comet. Many of our ice-core samples cover nearly an entire year, so they contribute less to an evaluation of the seasonality of extraterrestrial input. Some of our samples cover only part of a year, and these permit a more precise evaluation of the seasonality of extraterrestrial input.

To evaluate the seasonality of input of extraterrestrial debris, we constructed a time series from the estimated time range of each of the 10 samples that contained some cosmic debris. (There are intercalated samples that contain no cosmic debris.) We interpolated at daily intervals to produce a time series with

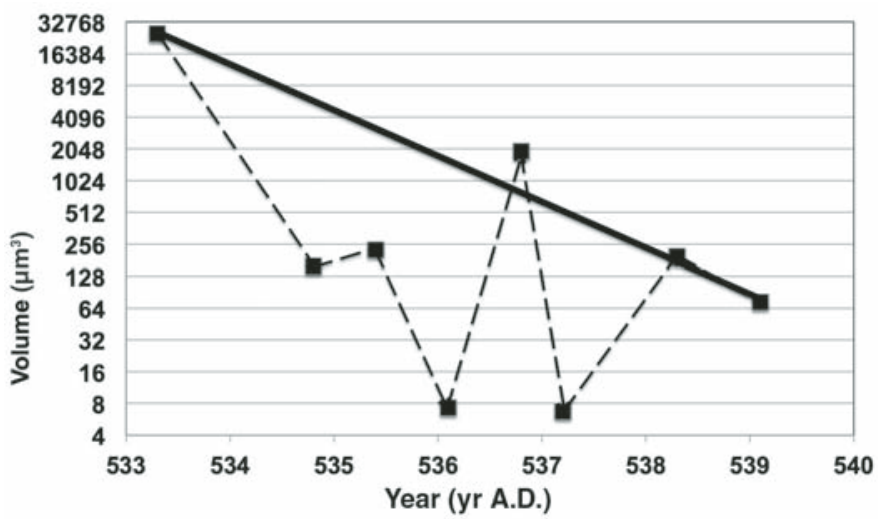

Figure 4. Change in volume of extraterrestrial material versus time in our ice-core samples. $Y$-axis is the log base 2 of the total volume in cubic micrometers of extraterrestrial material. Solid black line-estimate of the decline in volume of the largest samples over time if there was a single source of extraterrestrial material. Dashed lines-estimate of the change in volume over time if there were multiple sources of extraterrestrial material. 


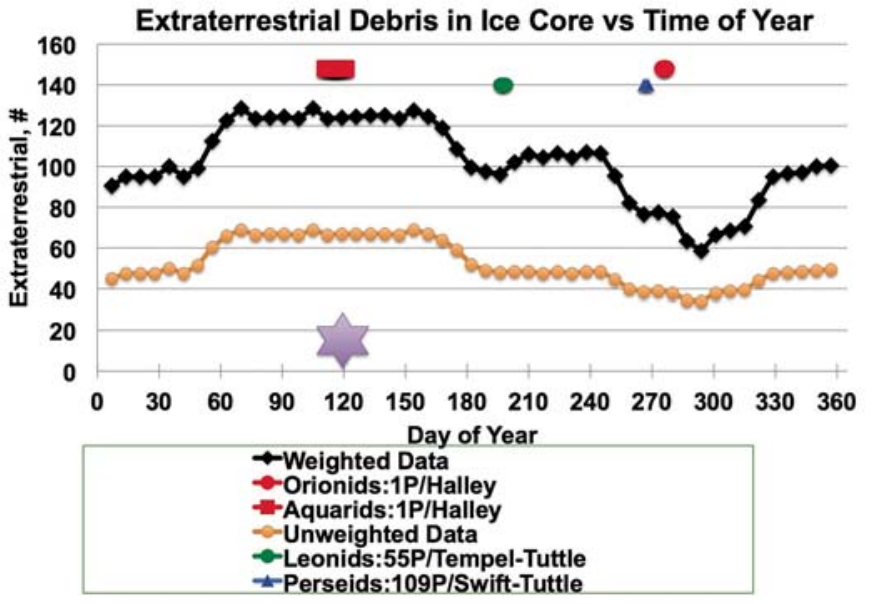

Figure 5. Seasonality of input of extraterrestrial dust particles. Black line with diamonds - total number of days in $2 \mathrm{wk}$ intervals with extraterrestrial particles as weighted by total number of particles per sample. Brown line with circles-total number of days in $2 \mathrm{wk}$ intervals with extraterrestrial particles. Red symbols-meteor showers derived from Comet 1P/Halley. Blue triangles-meteor shower derived from Comet 109P/Swift-Tuttle. Dark green circles-meteor shower derived from Comet 55P/Tempel-Tuttle. Purple star-most prominent peak in the number of meteor showers observed by Chinese astronomers prior to A.D. 918 (Yang et al., 2005).

one data point per day. To produce the weighted time series, we multiplied each time series of days of the year by the number of particles of cosmic debris in that particular sample. We then stacked both the weighted and unweighted time series to search for peaks in the seasonal input of cosmic debris. Finally, we reduced noise by summing and binning each time series over 2 wk intervals (Fig. 5).

Not every comet is a potential source of fine cosmic dust that might cloud Earth's atmosphere. Only a few comets pass close enough to Earth's orbit for Earth to cross their fields of abandoned debris. These latter comets are the main sources of meteor showers and cosmic dust on Earth.

During the first millennium A.D., ancient astronomers documented four meteor showers with known cometary associations: the Eta Aquarid, Orionid, Perseid, and Leonid meteor showers (Imoto and Hasegawa, 1958). The dates of these meteor showers were somewhat different during the sixth century A.D. (Table 5). With the exception of the Orionids, the adjusted dates for each shower came from models of three or more observations of each shower. The adjusted dates for the Orionids are from the two extant observations of this shower.

\section{Implications of Seasonality}

The seasonality of particle input suggests that comet 1P/ Halley was the main source of the extraterrestrial dust in the GISP2 core. Comet 1P/Halley passed near Earth in A.D. 530. The Chinese observed comet 1P/Halley between 29 August 530 A.D. and 27 September 530 A.D. Why was this particular apparition of comet 1P/Halley a significant source of extraterrestrial dust to Earth's atmosphere? One important variable is the amount of dust and vapor that degasses from the comet. Because degassing removes the black outer rind of a comet, it increases the brightness of the comet. Therefore, we use the absolute magnitude of a comet as a proxy for the intensity of cometary outgassing. Out of 22 apparitions of comet 1P/Halley between 239 B.C. and A.D. 1682, the comets of A.D. 530 and A.D. 1222 share the highest absolute magnitude of 5.5 (Kronk, 1984). We infer that comet $1 \mathrm{P} /$ Halley was ejecting unusually large amounts of dust and vapor during its A.D. 530 transit through the inner solar system.

\section{Modeling of Comet Intersections with Earth's Orbit}

Over time, the intersections of cometary debris trails with Earth's orbit slowly change. At present, Earth's orbit is most likely to intersect those of larger comet fragments when it crosses the path of prior passes of comet 2P/Encke during late June and early July. This is the time of the Taurid meteor showers. Two recent events are suspected of being caused by the Taurid meteor stream. The first was the Tunguska explosion on 30 June 1908. The second was a meteor storm on the Moon in June 1975 (Hartung, 1993). During the sixth century A.D., the most prominent intersection of Earth's orbit with a meteor shower was with the Eta Aquarid meteor shower of Comet 1P/Halley

\section{Orbital Simulations—Methods and Implications}

Orbital simulations were carried out using a software program for N-body integrations (Chambers, 1999). This technique considers the positions and velocities of all bodies in a system and predicts where each body will end up a short time later based on the combined gravitational pull caused by all other bodies. By repeating the calculations, the positions and

TABLE 5. DATES OF PROMINENT METEOR SHOWERS DURING THE SIXTH CENTURY A.D.

\begin{tabular}{|c|c|c|c|}
\hline Adjusted date & Day range & Meteors & Parent comet \\
\hline 27 Sep-9 Oct & $270-282$ & Leonids & 55P/Tempel-Tuttle \\
\hline 15 Jul-18 Jul & $196-199$ & Perseids & 109P/Swift-Tuttle \\
\hline 13 Apr-22 Apr & $103-112$ & Aquarids & 1P/Halley \\
\hline 23 Sep-25 Sep & 266-268 & Orionids & 1P/Halley \\
\hline
\end{tabular}


velocities of the bodies are established for a series of time increments. Similar integrations have been performed for comets over 400,000 yr (Valsecchi et al., 1995) and 40,000 yr periods (Harris and Bailey, 1998).

For this paper, simulations were performed over the past 6000 yr for short-period comets. In general, comets are usually on orbits that do not intersect Earth's orbit. With precession and perturbations of their orbits, there may be occasions when the orbits intersect. During such occasions, the node of the comet's orbit (where it intersects the ecliptic plane) will be equal to $1.0 \pm$ 0.05 astronomical units (au). From this simulation, Comet 1P/ Halley emerged as significant during the sixth century.

The orbital simulations have several important implications (Fig. 6). They suggest that the Eta Aquarid meteor shower, caused by the descending node of comet 1P/Halley's orbit, was an important source of meteors during the sixth century A.D. During the period from ca. A.D. 528 to 537, the descending node was closest to the plane of Earth's orbit. After the comet passed close to the sun in 530 A.D. (Fig. 6A), there could have been a renewed source of cometary debris to the Eta Aquarid meteor shower. As we will show, this debris may be related to subsequent climate downturns.
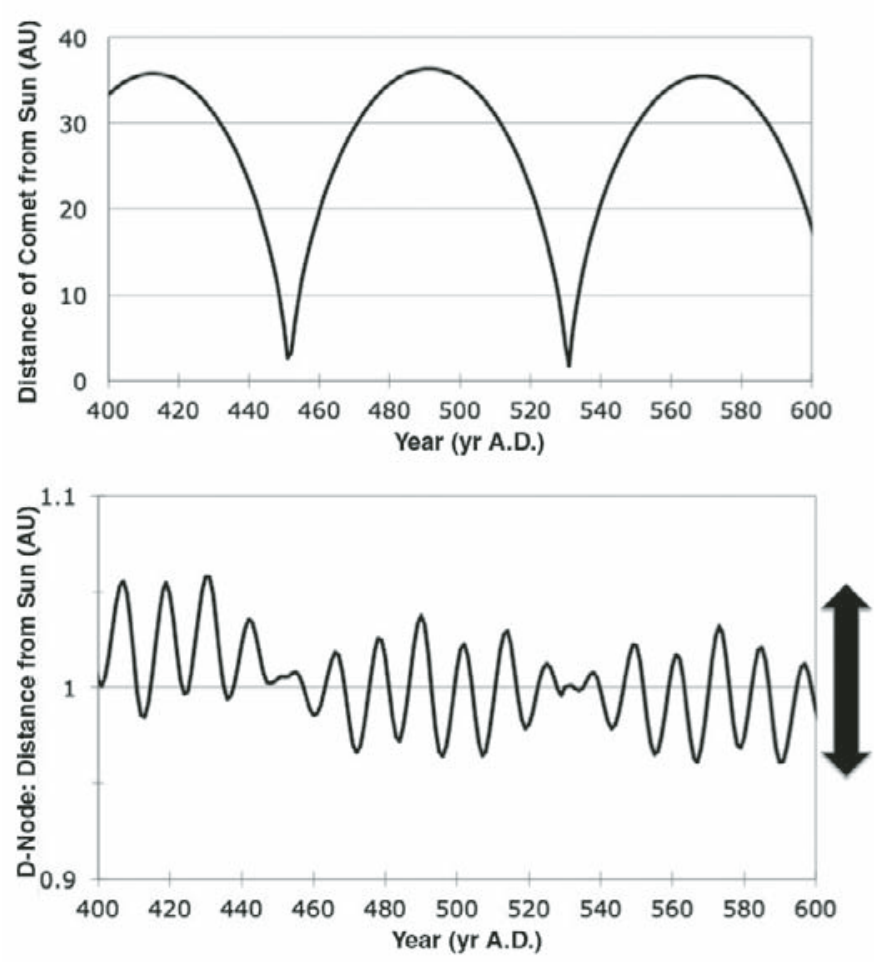

Figure 6. Comet 1P/Halley between A.D. 400 and 600. Distances are in au (astronomical units). (Top) Distance of 1P/Halley from the Sun. (Bottom) Distance of the descending node of Haley's orbit (source of Eta Aquarid meteor shower) from the Sun. Arrow on the right shows the range of distances of the orbital node (0.95-1.05 au) at which 1P/ Halley could be a source of debris for a meteor shower that would affect Earth.

\section{SEVERE CLIMATE DOWNTURN OF A.D 536-537}

Ancient histories have provided us with at least four contemporary accounts of a dramatic decrease in the Sun's brightness during A.D. 536 and 537 (Stothers, 1984). In Mesopotamia $\left(30-37^{\circ} \mathrm{N}\right)$, a source later quoted by Michael the Syrian (ca. 1166-1199 A.D.) and Bar-Hebraeus (ca. 1246-1286 A.D.) stated "in the year 848 of the Greeks [536 A.D.] ... the Sun was dark and its darkness lasted for eighteen months, each day it shone for about 4 hours, and still this light was only a feeble shadow... the fruits did not ripen and wine tasted like sour grapes" (translated to English from Chabot [in French], 1901 , p. 220-221). According to an anonymous writer, associated by tradition with Zacharius of Mytilene in Constantinople $\left(41^{\circ} \mathrm{N}\right.$ ) (Hamilton and Brooks, 1899, p. 267), "in the year 14 [536 A.D.]... the Sun began to be darkened by day and the Moon by night... from the 24th of March in this year until the 24th of June in the following year 15." Because the dimming was less severe and shorter in duration (15 mo instead of 18) at higher latitudes, it is generally agreed that the atmosphere was filled with fine dust from an unknown, low-latitude source. Volcanic ash and impact debris as the source of that dust are vigorously promoted by different writers (Rigby et al., 2004; Larsen et al., 2008).

\section{What Are the Forcing Factors for the Climate Downturn of A.D. 536-537?}

An increased input of extraterrestrial dust from A.D. 533 to 540 could have been one factor that contributed to the prominent climate downturn between A.D. 536 and 537. We know that there was also a modest volcanic eruption during this time that probably injected sulfate aerosols into the stratosphere early in A.D. 536. The question is whether the sulfate associated with this volcanic eruption was enough to have caused what is arguably the most significant solar dimming in the past $2000 \mathrm{yr}$. Our data suggest that the maximum volume of extraterrestrial dust loading was in A.D. 533. This is intriguing, as some tree rings record reduced growth, implying a modest climate cooling in A.D. 533 (Baillie, 2007). There is no record of a volcanic eruption at this time. Thus, high volumes of extraterrestrial dust could have dimmed Earth's atmosphere and cooled the climate in 533 A.D.

The problem with explaining the prominent climate downturn between A.D. 536 and 537 with a combination of extraterrestrial dust loading and a relatively small volcanic eruption is that the maximum volume of extraterrestrial dust was apparently around 16 times smaller in A.D. 536 than it was in A.D. 533 (Fig. 4). This amount of dust seems insufficient to force an unprecedented climate downturn. It is possible that there was an injection of fine-aerosol-size $(<\sim 0.5 \mu \mathrm{m}$ in diameter) extraterrestrial dust early in A.D. 536 that we did not observe due to our small sample sizes and relatively low magnifications. However, we should also ascertain if our data contain any evidence for another source of aerosol-sized dust. Next, we make a case for an additional source of dust beyond volcanic sulfate and extraterrestrial aerosols. 
Was There a Low-Latitude, Submarine Explosion Early in 536 A.D.?

Our ice-core data in two samples spanning the end of 535 and the start of A.D. 536 contain an unusual assemblage of marine and terrestrial microfossils. Based on our calendar-year time scale, we found and identified low-latitude diatoms and silicoflagellates in two samples centered at A.D. $535.4 \pm 0.4$ and $536.1 \pm 0.41$ (Appendix Table 1A). All but one of the 23 diatoms are marine. Based on the presence of Thalassiosira oestrupii var. oestrupii and Dictyocha stapedia, the A.D. $535.4 \pm 0.4-536.1 \pm$ 0.41 microfossil assemblage is most likely from a low latitude (Fig. 7).

Diatoms in general, and marine diatoms in particular, are rare in ice cores (Gayley and Ram, 1984; Burckle et al., 1988). So far as we know, no one had ever found diatoms in the GISP2 ice core before this research. Kellogg and Kellogg (2005) performed a search of the GISP2 core and found no diatoms. In addition, the concentration of diatoms at the A.D. $536 \pm 0.41$ level (667 diatoms/L) is the highest ever recorded in any ice core (Kellogg and Kellogg, 2005; Kellogg, 2010, written commun.).

The marine source of the diatoms and silicoflagellates is also unusual, given the elevation of $3203 \mathrm{~m}$ at the GISP2 site. Of the ice cores taken at elevations above $3000 \mathrm{~m}$ where diatoms have been found, nonmarine diatoms dominate the assemblages. Ninety-eight percent of the diatoms at Dome C (3240 m) in Antarctica are nonmarine (Burckle et al., 1988). In the Crete ice core from Greenland (elevation $3174 \mathrm{~m}$ ), 100\% of the diatoms are nonmarine (Gayley and Ram, 1984). In contrast, a comprehensive study of 136 samples from the South Pole water well (elevation $2835 \mathrm{~m}$ ) found 29\% nonmarine diatoms (Kellogg and Kellogg, 1996; Kellogg, 2010, written commun.).

The characterization of the diatoms in meltwater from the South Pole water well is the most detailed we know of (Kellogg and Kellogg, 1996, 2005). Tom Kellogg (2010, written commun.) sent us his data on the number of diatoms versus depth and the volume of water filtered per sample. The maximum number of diatoms per liter in the South Pole water well is 455 diatoms/L. Our water samples are much smaller (27$102 \mathrm{~mL}$; Appendix Table 1A) than theirs (modal volumes of $800-900 \mathrm{~mL}$ ). If our diatom count is spread over non-diatombearing samples from the stratigraphic levels immediately above and below them $(328 \mathrm{~mL}$ of water total), the diatom count averages 79 diatoms/L of water. Of the 136 samples from the South Pole water well, five contained more than 79 diatoms/L of water. Thus, the diatom concentrations that we found are high but not unprecedented.

Kellogg and Kellogg (1996, 2005) identified 1179 diatoms from the South Pole water well. They identified 839 specimens of marine diatoms. All but two marine diatoms are high latitude or cosmopolitan. A single high-latitude diatom and a single Miocene-age diatom were found in the two samples with the highest concentrations of diatoms and over 100 diatoms total. Their detailed study shows that low-latitude diatoms are some- times moved to high latitudes, but such transport is rare. Other workers found evidence that diatoms are ablated from Antarctic ice and subsequently blown elsewhere by the wind (McKay et al., 2008). Although some marine diatoms are present, the windblown assemblages are dominated by terrestrial species. The diatom surfaces appear ablated and smoothed, as would be expected for reworked material (see figures in McKay et al., 2008). In contrast, our diatoms exhibit clear, sharp surface textures (Fig. 7). Thus, our finding of a dominantly marine, well-preserved, lowlatitude assemblage of diatoms in a high-altitude ice core is not matched in previous studies.
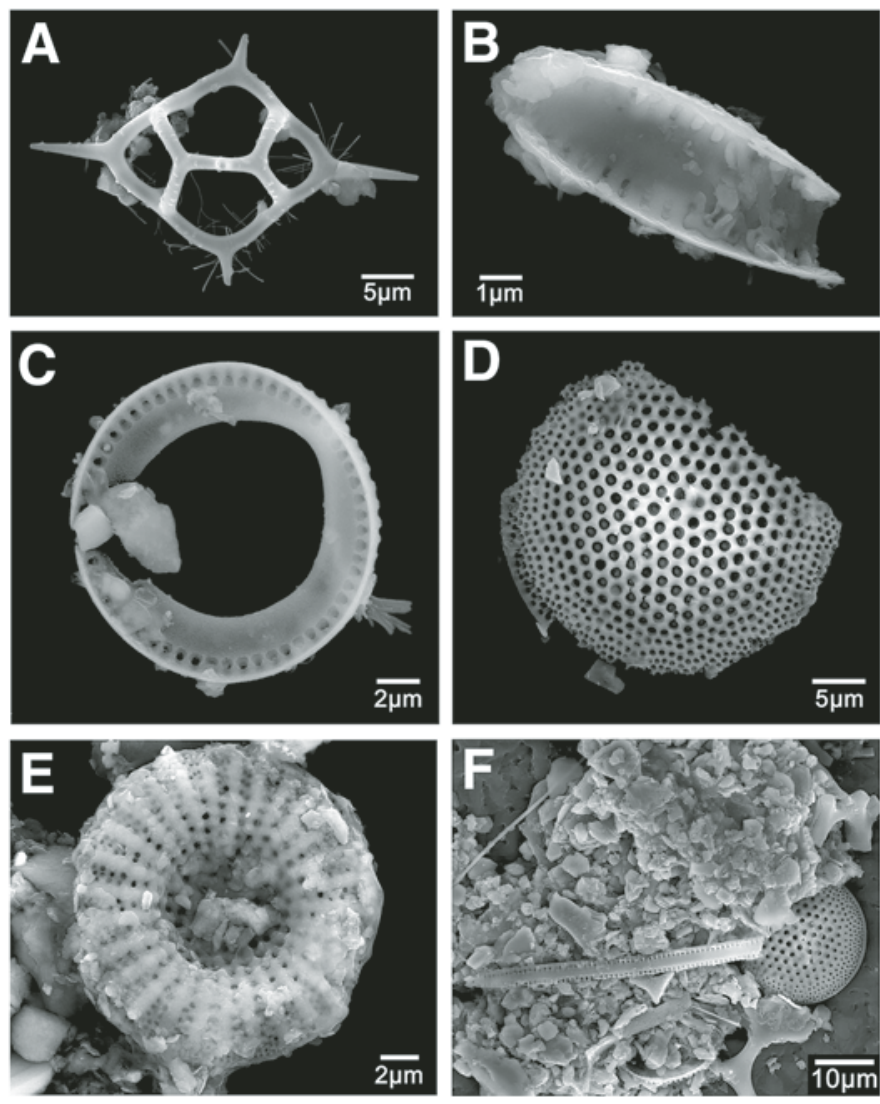

Figure 7. Scanning electron microscope (SEM) micrographs of marine microfossils from the Greenland Ice Sheet Project 2 (GISP2) core: (A-E) A.D. $536 \pm 0.41$ and (F) A.D. $535 \pm 0.4$. The total number of occurrences follows each species name. (A) Dictyocha stapedia haeckel (1), an equatorial to subequatorial marine silicoflagellate; (B) Opephora (1), a benthic marine diatom; (C) girdle band from marine diatom Thalassiosira oestrupii (4); (D) Thalassiosira oestrupii var. oestrupii (7), a marine equatorial to subequatorial planktonic diatom; (E) Cyclostephanos sp. (1), a nonmarine planktonic diatom; (F) marine planktonic diatoms Thalassiosira oestrupii var. oestrupii (right) and Thalassiothrix (left middle) (5). Total diatoms: A.D. $536 \pm$ 0.41 layer (23); A.D. $535 \pm 0.4$ layer (3). Ratios of backscattered and secondary electron imaging modes were chosen to maximize the display of the images: A, D, F: 50\% ILSE (in-lens secondary electron mode), 50\% BSE (backscattered electron mode); B: 100\% SE2 (standard secondary electron mode); C, E: 50\%SE2, 50\% BSE. 


\section{Provenance of Marine Microfossils}

The marine silicoflagellate is from equatorial to subtropical latitudes (Barron and Bukry, 2007). Thalassiosira oestrupii is identified as the variety oestrupii on the basis of its diameter (Lloyd Burckle, 2010, oral commun.). Thalassiosira oestrupii, a tropical to subtropical diatom, can occur at higher latitudes but is abundant $(>10 \%)$ only in low-latitude assemblages. Our assemblage is $>20 \%$ Thalassiosira oestrupii (Burckle, 1977). Opephora is a benthic marine diatom. Because they are photosynthetic, benthic diatoms live within the photic zone at water depths shallower than $\sim 100 \mathrm{~m}$, so their presence in oceanic sediments normally indicates proximity to land. The other marine diatoms are planktonic. The occurrence of the terrestrial diatom Cyclostephanos is suggestive of a continental margin environment (Abrantes, 2007). If all of the diatoms and the silicoflagellate are from the same location, they are from a continental margin at water depths of less than $100 \mathrm{~m}$ in the tropics or subtropics.

\section{Marine Dust as an Additional Forcer of the A.D. 536-537 Climate Downturn}

Some of the diatoms are found among piles of particles (Fig. 7E). We suggest that the marine sediment containing these diatoms and associated fine particles may have provided an additional source of dust during the severe climate downturn between A.D. 536 and 537. The dominant component of the dust may be constrained by the presence of high $\mathrm{Ca}(574.8 \mu \mathrm{g} / \mathrm{L})$ at the A.D. 536 level. This is the highest $\mathrm{Ca}$ value in our ion data (Table 1, sample 7; Abbott et al., this volume, Chapter 22). In general, high $\mathrm{Ca}$ values in ion data are considered to be a proxy for $\mathrm{CaCO}_{3}$ dust (Zdanowicz et al., 2000; Bory et al., 2003; Kang et al., 2003; Fischer et al., 2007), which is usually interpreted as being terrestrial dust. The finding of low-latitude marine microfossils suggests another interpretation-the high $\mathrm{Ca}$ as derived from marine carbonate dust. Because sulfate aerosols from Icelandic volcanic eruptions acidify the snow at the GISP2 site, calcium carbonate is usually not preserved. Instead, the calcium carbonate is dissolved and contributes Ca to meltwater (ion data) derived from the ice.

The concentration of $\mathrm{Ca}$ at the A.D. 536 level is one of the highest ever observed. For example, the average $\mathrm{Ca}$ concentration in the detailed ion data from 96 to $593 \mathrm{~m}$ depth (GISP2-D) is $7.2 \mu \mathrm{g} / \mathrm{L}$ (Mayewski et al., 1997). The maximum Ca concentration is $87 \mu \mathrm{g} / \mathrm{L}$. This depth interval represents over $2000 \mathrm{yr}$ of time ( $259 \mathrm{yr}$ B.P. to $2589 \mathrm{yr}$ B.P.). If the Ca value of $575 \mu \mathrm{g} / \mathrm{L}$ is a proxy for dust and by implication dust loading of the atmosphere, then the dust loading is $\sim 80$ times the background level. We do not know how much fine dust/aerosol was needed to produce the A.D. 536 solar dimming, but 80 times the background level seems promising.

We found calcium carbonate crystals in the same samples as those containing tropical diatoms. The calcium carbonate is in the form of single crystals or crystal aggregates (Fig. 8). Calcium carbonate often precipitates within sediments during diagenesis. However, diagenetic $\mathrm{CaCO}_{3}$ precipitates have many morphologies, and only a few are equant single crystals (Morse et al., 2007; Dupraz et al., 2009; Moore and Wade, 2013). It is common for marine microfossils and nannofossils to become more coarsely crystalline during early diagenesis (Reid and Macintyre, 1998; Crudeli et al., 2004). If broken, these coarsely crystalline carbonate aggregates may appear hollow. The presence of hollow $\mathrm{CaCO}_{3}$ aggregates could mean that the fine $\mathrm{CaCO}_{3}$ crystals in our ice-core particles are primary rather than secondary. The single crystals in our samples may represent either broken fragments of the hollow aggregates or diagenetic carbonate crystals derived directly from low-latitude marine sediment. Either of these origins would mean that the fine calcium carbonate crystals were suspended in the atmosphere before they and the diatoms were deposited in Greenland.

The individual $\mathrm{CaCO}_{3}$ crystals are typically less than $1 \mu \mathrm{m}$ in diameter (Fig. 8A). This puts these crystals into the aerosol size range. Aerosols can remain in the stratosphere for over a year. Calcium carbonate is typically white or light gray in color. Black aerosols like black carbon act as black bodies that absorb heat (Jacobson, 2001; Roberts and Jones, 2004; Ramanathan and Carmichael, 2008). White or light-gray aerosols reflect sunlight and nucleate clouds, helping to cool the climate. Thus, if significant percentages of the fine carbonate crystals were primary, they could be the reason it became cold and dark during A.D. 536 and 537. We will not know until we can examine less acid ice from Antarctica covering the same time period.

In addition to calcium carbonate aggregates, we found one distinctive plagioclase feldspar grain at the same stratigraphic level. The grain has micro-offsets in directions that define a staircase-like pattern (Figs. 8B and 8C). It is possible that this is the ladder structure found in impact ejecta (French, 1998), but we cannot be sure without further study, which is impossible (for us) with such small grains.

The source of the explosion that transported diatoms, feldspar, and possibly carbonate dust from low latitudes to Greenland is still in question. Recent work has shown that terrestrial diatoms can be lofted high into the atmosphere during explosive volcanic eruptions (Van Eaton et al., 2013); thus, the occurrence of diatoms is not by itself a marker for any particular type of explosion. Because transport from low latitudes to the poles is most probable in the stratosphere, a large explosion is required. Regardless of whether the dimming was primarily produced by mineral aerosols or sulfate aerosols, the aerosols must have resided in the stratosphere for 15$18 \mathrm{mo}$. The primary source of the explosion can be determined by a combination of microprobe work on possible volcanic glass particles in the GISP2 core and an assessment of the types of particles within the portions of Antarctic ice cores dating to ca. A.D. 536-537. 


\section{MASS EXTINCTIONS-RELEVANCE AND APPLICATIONS}

Our work on the GISP2 ice core shows the complications that are present in a $10 \mathrm{yr}$ period involving one or more extraterrestrially driven perturbations of the climate with some additional forcing from volcanic sulfate aerosols. Although only the Cretaceous-Tertiary mass extinction has unequivocal evidence of extraterrestrial input, some studies suggest that coupling of both volcanism and impact are needed to produce extinctions.
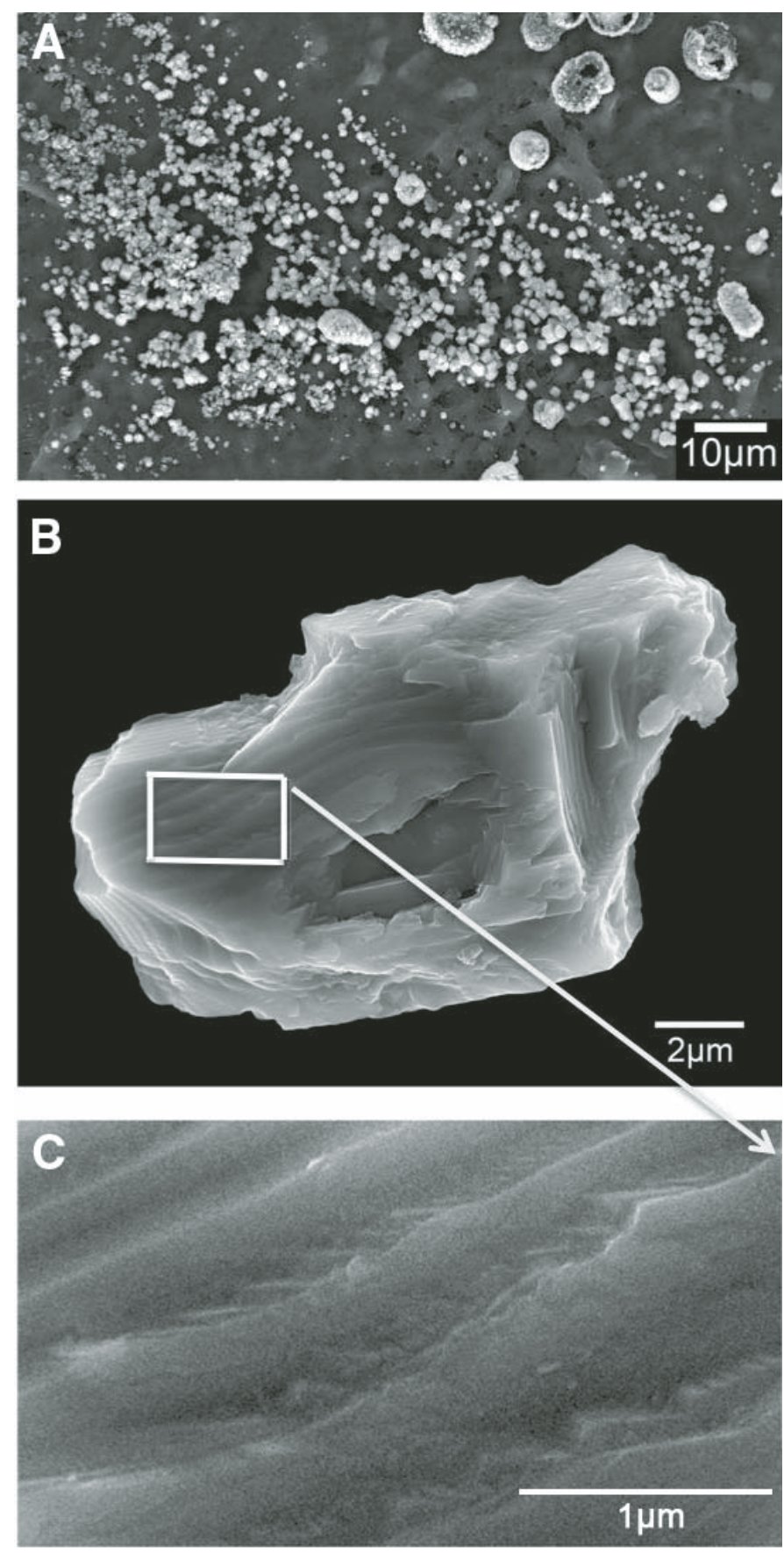

If the terrestrial system is stressed by large-scale volcanism, a large impact event could provide the coup de grâce. Therefore, we favor the pulse-press model of mass extinctions with coupled volcanic and extraterrestrial (or other) forcing (Arens and West, 2008).

The largest extraterrestrial bodies are comets, not asteroids. Ninety-five percent of the extraterrestrial bodies big enough to produce a large impact crater (20-100 km in diameter) are comets (Hughes, 1998). For impact craters over $100 \mathrm{~km}$ in diameter, the proportion of comets will be even higher. The problem is how to detect their signal in the geological record. This is not easy. There are still arguments about the cometary versus asteroidal nature of the $65 \mathrm{Ma}$ Cretaceous-Tertiary impactor (Hut et al., 1987; Bottke et al., 2007). Our study suggests another novel marker for extraterrestrial input that may help to distinguish cometary from asteroidal sources.

\section{Improved Strategies for Finding Extraterrestrial Markers}

Another problem in detecting extraterrestrial inputs to mass extinctions is that the signal of extraterrestrial forcing is confined to a narrow stratigraphic interval and may be obscured by diagenesis, erosion, or tiny grain size. We show two examples in the following section.

In the past, bulk chemical analyses for Ir, Pt, and Ni have been the method of choice, along with a search for shocked quartz. The Cretaceous-Tertiary impact event was relatively "easy" to prove because it was partially on land and occurred at a time when the Atlantic Ocean was narrow. In the case of a distal oceanic impact in the middle of a paleo-Pacific Ocean, both bulk chemical analyses and searches for shocked quartz are less likely to yield results. Because the shock lamellae in the largest quartz grains are annealed out with increasing distance from an impact site (Croskell et al., 2002), the preserved, still-shocked grains are very small. For example, the average size of distal ejecta grains deposited $5000 \mathrm{~km}$ away from an abyssal crater is $\sim 10-32 \mu \mathrm{m}$ (Collins et al., 2005) for impacts with recurrence intervals up to the length of the Phanerozoic (Fig. 9). This is far below the minimum grain size of $\sim 125 \mu \mathrm{m}$ that is needed to make a good thin section of shocked quartz. Thus, any plausible size of impactors hitting near the center of a paleo-Pacific Ocean at an average abyssal water depth of $3800 \mathrm{~m}$ (Parsons and Sclater, 1977) would be unlikely to produce a detectable, verifiable layer of shocked quartz on land.

Figure 8. Scanning electron microscope (SEM) micrographs of unusual grains from stratigraphic level containing marine diatoms. (A) $\mathrm{CaCO}_{3}$ crystals. Micrograph image is $50 \%$ BSE (backscattered electron mode), 50\% SE2 (standard secondary electron mode). Aggregates of crystal on upper right may represent recrystallized nanofossils. (B) Feldspar grain with unusual cleavage patterns. Micrograph 50\% BSE, 50\% ILSE (in-lens secondary electron mode). (C) Enlargement of area inside of white rectangle in $\mathrm{B}$. 
Bulk chemical analyses for Ir, Pt, and Ni may be affected by the development of water-soluble chlorides during a major oceanic impact. We know that these elements exhibit similar chemical behavior and are often associated with Fe. Although the carrier phases for Ir and $\mathrm{Pt}$ are uncertain, both $\mathrm{Fe}$ and Ni weather to form water-soluble salts, in particular, $\mathrm{Fe}$ and $\mathrm{Ni}$ chlorides. In one study of polar snow, $\sim 35 \%$ of the $\mathrm{Ni}$ was estimated to reside in a water-soluble Ni salt (Brocas and Picciotto, 1967). Because most of the $\mathrm{Cl}$ within polar snow and ice comes from sea salt (O'Brien et al., 1995), we suggest that an abyssal oceanic impact might produce water-soluble salts of $\mathrm{Ni}$, Ir, and $\mathrm{Pt}$ within the impact ejecta layer. If so, these soluble salts would make it difficult to preserve a local peak in $\mathrm{Ir}, \mathrm{Pt}$, or $\mathrm{Ni}$ over geological time. (Interestingly, only one out of five of the known tektite strewn fields has a significant Ir anomaly [Glass, 1990; Koeberl and Shirey, 1993].)

Recent research has found a new marker for extraterrestrial inputs by examining small particles: Fe-Ni silicides (formation temperature $>2000{ }^{\circ} \mathrm{C}$ ) within impact spherules ( $\mathrm{Wu}$ et al., 2013). This particular spherule-bearing layer does not produce a detectable Ir anomaly in analyses of the bulk sediment. Our ice-core results further suggest that examination of individual small particles can complement bulk analyses. The finer particles should be examined for shocked ilmenite (Sclar et al., 1973; Harris et al., 2005) and cometary markers such as excess $\mathrm{Sn}$ and noble gases. Although noble gases are removed by heating the sediment to temperatures above $70{ }^{\circ} \mathrm{C}$ (Farley et al., 2005), the other markers can survive lowgrade metamorphism.

Because atmospheric deposition of fine particles is often enhanced at high latitudes (Megner et al., 2008), extinctionlevel stratigraphic sections with high paleolatitudes are preferred if they exist. At Cenozoic-age high-latitude sites, out-of-place equatorial diatoms or foraminifera might provide marker horizons. In addition, many of the stratigraphic markers for impact either are intrinsically magnetic (e.g., shocked ilmenite, magnetic spherules, Fe-Ni silicides) or are typically associated with $\mathrm{Fe}$ oxide (Sn-rich particles). Magnetic separation of disaggregated sediment followed by examination of the magnetic fine particles may produce more reliable results.

\section{CONCLUSIONS}

Cometary dust is the probable source of micrometer-sized C-rich, Sn-rich particles found at four stratigraphic levels in the GISP2 ice core. The input of extraterrestrial dust is concentrated in late spring, suggesting that dust from Comet 1P/Halley contributed to increased opacity of Earth's atmosphere between A.D. 533 and 540. High volumes of cometary dust in A.D. 533 may have caused the minor climate downturn recorded by tree rings and historical sources. Later on, in A.D. 536 and 537, the volumes of cometary dust were possibly much smaller but with an uncertain contribution from fine-aerosol-sized particles. Atmospheric aerosols derived from multiple sources mostly likely produced the profound solar dimming in A.D. 536 and 537. By analogy, synergistic catastrophic events may also cause mass extinctions. Detailed examinations of fine particles may complement previous methods of testing models of synergistic impact and volcanic drivers of mass extinctions.

\section{ACKNOWLEDGMENTS}

We thank Jihong Cole-Dai for the ion data on our supernatant water samples. We are grateful to the Lamont-Doherty Earth Observatory Climate Center for their support of our laboratory and analytical costs. This work would have been impossible without their generous support and encouragement. We thank anonymous reviewers for helpful reviews. We thank the Electron Microscopy Center at The City College of New York for access to their facilities.

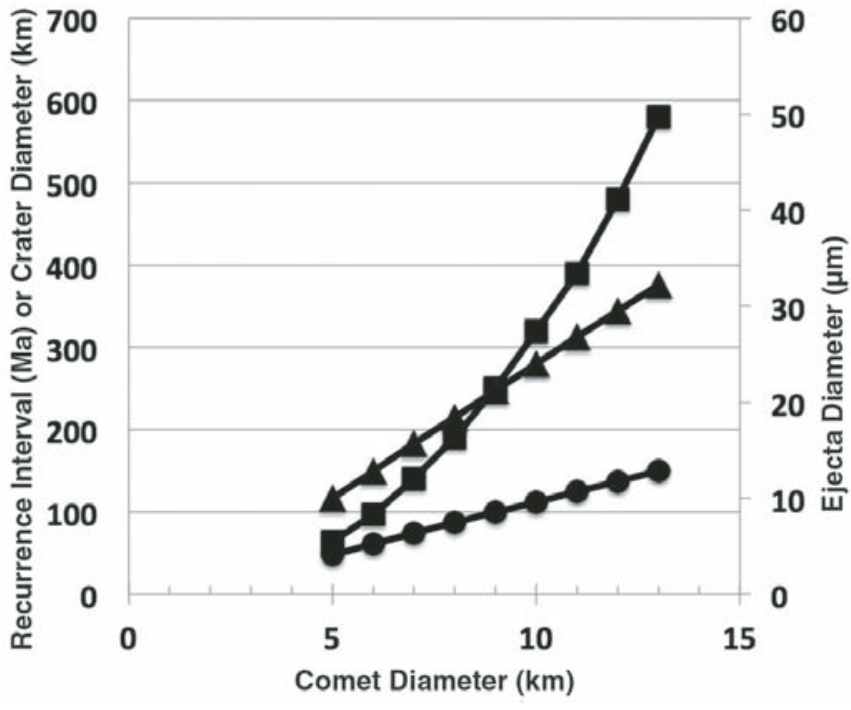

\section{-Ma between impacts of this size}

-Crater diameter, km
in $\mathbf{3 8 0 0 ~ m}$ of water

-Diameter ejecta,
micrometers at
$\mathbf{5 0 0 0 ~} \mathbf{~ k m}$

Figure 9. Models of ejecta diameter for comets hitting in the middle of a paleoPacific Ocean, $5000 \mathrm{~km}$ from any site on land. The models are for comets between 5 and $13 \mathrm{~km}$ in diameter hitting at the average oceanic water depth of $3800 \mathrm{~m}$. Black squares-impactor diameter in kilometers. Black circles-average recurrence interval of the impactor in millions of years. Black triangles-average ejecta diameter in micrometers. 


\section{APPENDIX 1}

Appendix 1 (Appendix Table 1A) contains the metadata and data for all of the samples analyzed for ions and particles. The data in this appendix will provide a framework for comparison of our data to other data sets from the GISP2 core.

\section{APPENDIX 2}

Appendix 2 (Appendix Table 1B) contains representative EDS analyses of clean quartz grains. This data shows the background levels of carbon measured on clean quartz that was not carbon coated.

APPENDIX TABLE 1A. TIME SCALE AND VOLUMES OF WATER CENTRIFUGED TO DERIVE PARTICLES

\begin{tabular}{|c|c|c|c|c|}
\hline Sample no. & $\begin{array}{c}\text { Meltwater } \\
(\mathrm{mL})\end{array}$ & $\begin{array}{c}\text { Depth range } \\
(\mathrm{m})\end{array}$ & $\begin{array}{c}\text { Age } \\
\text { (yr A.D., Meese-Sowers) }\end{array}$ & $\begin{array}{c}\text { Age } \\
\text { (yr A.D., adjusted) }\end{array}$ \\
\hline$\overline{1 \mathrm{~A}}$ & 33 & $360-360.1$ & $543.8 \pm 3.26$ & $541.8 \pm 0.26$ \\
\hline $1 \mathrm{~B}$ & 42 & $360.1-360.2$ & $543.3 \pm 3.26$ & $541.3 \pm 0.26$ \\
\hline $2-S 1$ & 51 & $360.2-360.38$ & $542.6 \pm 3.46$ & $540.6 \pm 0.46$ \\
\hline $2-S 2$ & 51 & $360.2-360.38$ & $542.6 \pm 3.46$ & $540.6 \pm 0.46$ \\
\hline $3-S 1$ & 45 & $360.38-360.51$ & $541.8 \pm 3.33$ & $539.8 \pm 0.33$ \\
\hline $3-S 2$ & 45 & $360.38-360.51$ & $541.8 \pm 3.33$ & $539.8 \pm 0.33$ \\
\hline $4 A-S 1$ & 39 & $360.51-360.64$ & $541.1 \pm 3.33$ & $539.1 \pm 0.33$ \\
\hline 4A-S2 & 32.5 & $360.51-360.64$ & $541.1 \pm 3.33$ & $539.1 \pm 0.33$ \\
\hline 4B & 38.5 & $360.64-360.7$ & $540.6 \pm 3.15$ & $538.6 \pm 0.15$ \\
\hline $4 C$ & 40 & $360.7-360.77$ & $540.3 \pm 3.18$ & $538.3 \pm 0.18$ \\
\hline $5 \mathrm{~A}$ & 30 & $360.77-360.84$ & $540 \pm 3.18$ & $538 \pm 0.18$ \\
\hline $5 B$ & 34 & $360.84-360.92$ & $539.6 \pm 3.2$ & $537.6 \pm 0.2$ \\
\hline $5 \mathrm{C}$ & 52 & $360.92-361$ & $539.2 \pm 3.2$ & $537.2 \pm 0.2$ \\
\hline 6 & 42 & $361-361.08$ & $538.8 \pm 3.2$ & $536.8 \pm 0.2$ \\
\hline 7 & 33 & $361.08-361.24$ & $538.1 \pm 3.41$ & $536.1 \pm 0.41$ \\
\hline 8 & 37 & $361.24-361.39$ & $537.4 \pm 3.38$ & $535.4 \pm 0.38$ \\
\hline 9 & 27 & $361.39-361.45$ & $536.8 \pm 3.15$ & $534.8 \pm 0.15$ \\
\hline $10 \mathrm{~A}$ & 32.5 & $361.45-361.55$ & $536.4 \pm 3.26$ & $534.4 \pm 0.26$ \\
\hline $10 B$ & 32.5 & $361.55-361.64$ & $535.9 \pm 3.23$ & $533.9 \pm 0.23$ \\
\hline $11-S 1$ & 46 & $361.64-361.8$ & $535.3 \pm 3.41$ & $533.3 \pm 0.41$ \\
\hline $11-S 2$ & 47 & $361.64-361.8$ & $535.3 \pm 3.41$ & $533.3 \pm 0.41$ \\
\hline $12 \mathrm{~A}$ & 46 & $361.8-361.9$ & $534.6 \pm 3.26$ & $532.6 \pm 0.26$ \\
\hline $12 B$ & 45 & $361.9-362$ & $534.1 \pm 3.26$ & $532.1 \pm 0.26$ \\
\hline
\end{tabular}

Note: The Meese-Sowers time scale (Meese et al., 1997) is primarily derived from annual layer counts that rely on the formation of coarsegrained hoar layers during the Arctic summer (Alley et al, 1997). When the annual signal is poorly resolved in visual stratigraphy, it is supplemented by measurements of electrical conductivity, oxygen isotopes, laser light scattering of dust, and major ion chemistry.

APPENDIX TABLE 1B. SEMIQUANTITATIVE ENERGY-DISPERSIVE SPECTROMETRY ANALYSES OF CLEAN TERRESTRIAL QUARTZ GRAINS IN LEVEL 11

\begin{tabular}{|c|c|c|c|c|}
\hline Sample no. & $\begin{array}{c}\mathrm{C} \\
\text { (wt\%) }\end{array}$ & $\begin{array}{c}\mathrm{O} \\
\text { (wt\%) }\end{array}$ & $\begin{array}{c}\mathrm{Si} \\
\text { (wt\%) }\end{array}$ & $\overline{\text { Total }}$ \\
\hline $11-20$ & 1.7 & 42 & 54.4 & 98.1 \\
\hline $11-19$ & 2.9 & 39.3 & 55.5 & 97.7 \\
\hline $11-31$ & 2.8 & 43 & 52.4 & 98.2 \\
\hline $11-39$ & 1.7 & 41.6 & 54.2 & 97.5 \\
\hline Average & 2.3 & 41.5 & 54.1 & \\
\hline
\end{tabular}

\section{REFERENCES CITED}

Abbott, D.H., Breger, D., Biscaye, P.E., and Juhl, R.A., 2014, this volume, Chapter 22, Calendar-year dating of the Greenland Ice Sheet Project 2 (GISP2) ice core from the early sixth century using historical, ion, and particulate data, in Keller, G., and Kerr, A.C., eds., Volcanism, Impacts, and Mass Extinctions: Causes and Effects: Geological Society of America Special Paper 505, doi:10.1130/2014.2505(22).

Abrantes, F., 2007, Marine diatoms, in Elias, S.A., ed., Encyclopedia of Quaternary Sciences: Amsterdam, Elsevier, p. 1668-1678.

Alexander, C.O.D., Bowden, R., Fogel, M.L., Howard, K.T., Herd, C.D.K., and Nittler, L.R., 2012, The provenances of asteroids, and their contributions to the volatile inventories of the terrestrial planets: Science, v. 337, p. 721-723, doi:10.1126/science. 1223474 .
Alley, R.B., Shuman, C.A., Meese, D.A., Gow, A.J., Taylor, K.C., Cuffey, K.M., and Elder, B., 1997, Visual-stratigraphic dating of the GISP2 ice core: Basis, reproducibility, and application: Journal of Geophysical Research, v. 102, p. 26,367-26,381, doi:10.1029/96JC03837.

Arens, N.C., and West, I.D., 2008, Press-pulse: A general theory of mass extinction?: Paleobiology, v. 34, p. 456-471, doi:10.1666/07034.1.

Baillie, M.G., 1999, Exodus to Arthur: Catastrophic Encounters with Comets: London, UK, Batsford, $256 \mathrm{p}$.

Baillie, M.G.L., 2007, Tree-rings indicate global environmental downturns that could have been caused by comet debris, in Bobrowsky, P.T., and Rickman, H., eds., Comet/Asteroid Impacts and Human Society: Berlin, Springer, p. 105-122.

Bar-Hebraus, [ca. 1246-1286], 1932, Chronography (translated by Budge, E.A.W.): London, Oxford University Press. 
Barron, J.A., and Bukry, D., 2007, Development of the California Current during the past 12,000 years based on diatoms and silicoflagellates: Palaeogeography, Palaeoclimatology, Palaeoecology, v. 248, p. 313-338, doi:10.1016/j.palaeo.2006.12.009.

Bory, A.J.-M., Biscaye, P.E., Piotrowski, A.M., and Steffensen, J.P., 2003, Regional variability of ice core dust composition and provenance in Greenland: Geochemistry Geophysics Geosystems, v. 4, no. 12, p. 1107, doi:10.1029/2003GC000627.

Bottke, W.F., Vokrouhlický, D., and Nesvorný, D., 2007, An asteroid breakup $160 \mathrm{Myr}$ ago as the probable source of the K/T impactor: Nature, v. 449 , p. 48-53, doi:10.1038/nature06070.

Bradley, J.P., and Brownlee, D.E., 1986, Cometary particles: Thin sectioning and electron beam analysis: Science, v. 231, p. 1542-1544, doi:10.1126/ science.231.4745.1542.

Bradley, J.P., Keller, L.P., Snow, T.P., Hanner, M.S., Flynn, G.J., Gezo, J.C., and Bowey, J.E., 1999, An infrared spectral match between GEMS and interstellar grains: Science, v. 285, p. 1716-1718, doi:10.1126/ science.285.5434.1716.

Brocas, J., and Picciotto, E., 1967, Nickel content of Antarctic snow: Implications of the influx rate of extraterrestrial dust: Journal of Geophysical Research, v. 72, p. 2229-2236, doi:10.1029/JZ072i008p02229.

Brook, E., Kurz, M., Curtice, J., and Cowburn, S., 2000, Accretion of interplanetary dust in polar ice: Geophysical Research Letters, v. 27, p. 3145 3148, doi:10.1029/2000GL011813.

Brook, E., Kurz, M.D., and Curtice, J., 2009, Flux and size fractionation of He-3 in interplanetary dust from Antarctic ice core samples: Earth and Planetary Science Letters, v. 286, p. 565-569, doi:10.1016/j.eps1.2009.07.024.

Brownlee, D.E., 1987, Morphological, chemical and mineralogical studies of cosmic dust: Philosophical Transactions of the Royal Society of London, ser. A, Mathematical and Physical Sciences, v. 323, p. 305-311, doi:10.1098/rsta.1987.0087.

Burckle, L.H., 1977, Pliocene and Pleistocene diatom levels from the equatorial Pacific: Quaternary Research, v. 7, p. 330-340, doi:10.1016/0033 -5894(77)90025-4.

Burckle, L.H., Gayley, R.I., Ram, M., and Petit, J.R., 1988, Biogenic particles in Antarctic ice cores and the source of Antarctic dust: Antarctic Journal of the United States, v. 23, p. 71-72.

Chambers, J.E., 1999, A hybrid symplectic integrator that permits close encounters between massive bodies: Monthly Notices of the Royal Astronomical Society, v. 304, p. 793-799, doi:10.1046/j.1365-8711.1999.02379.x.

Ciucci, A., Rietmeijer, F.J.M., Della Corte, V., Brunetto, R., de Angelis, S., Palumbo, P., and Rotundi, A., 2010, Collecting dust in the upper stratosphere at high latitudes: Constraints on the compositions of cosmic dust particles, in Proceedings European Planetary Science Congress, Volume 1: Rome, Italy, European Planetary Science Congress, p. 175

Collins, G.S., Melosh, H.J., and Marcus, R.A., 2005, Earth impact effects program: A Web-based computer program for calculating the regional environmental consequences of a meteoroid impact on Earth: Meteoritics \& Planetary Science, v. 40, p. 817-840, doi:10.1111/j.1945-5100.2005 .tb00157.x.

Croskell, M., Warner, M., and Morgan, J., 2002, Annealing of shocked quartz during atmospheric re-entry: Geophysical Research Letters, v. 29, p. 1-1-1-4.

Crudeli, D., Young, J.R., Erba, E., de Lange, G.J., Henriksen, K., Kinkel, H., and Ziveri, P., 2004, Abnormal carbonate diagenesis in Holocene-late Pleistocene sapropel-associated sediments from the Eastern Mediterranean; evidence from Emiliania huxleyi coccolith morphology: Marine Micropaleontology, v. 52, p. 217-240, doi:10.1016/j.marmicro.2004.04.010.

Delsemme, A.H., 1991, Cometary origin of carbon, nitrogen and water on the Earth: Origins of Life and Evolution of the Biosphere, v. 21, p. 279-298, doi:10.1007/BF01808303.

Dikov, Y.P., Ivanov, A.V., Wlotzka, F., Galimov, E.M., and Wänke, H., 1998, High enrichment of carbon and volatile elements in the surface layers of Luna 16 soil sample 1635: Result of comet or meteorite impact?: Earth and Planetary Science Letters, v. 155, p. 197-204, doi:10.1016/S0012821X(97)00212-4.

Dupraz, C., Reid, R.P., Braissant, O., Decho, A.W., Norman, R.S., and Visscher, P.T., 2009, Processes of carbonate precipitation in modern microbial mats: Earth-Science Reviews, v. 96, p. 141-162.

Engrand, C., 2011, Meteorites and cosmic dust: Interstellar heritage and nebular processes in the early solar system: European Physical Journal Web of Conferences, v. 18, p. 5001-5026, doi:10.1051/epjconf/20111805001.
Engrand, C., and Maurette, M., 1998, Carbonaceous micrometeorites from Antarctica: Meteoritics \& Planetary Science, v. 33, p. 565-580, doi:10.1111/j.1945-5100.1998.tb01665.x.

Farley, K.A., Love, S.G., and Patterson, D.B., 1997, Atmospheric entry heating and helium retentivity of interplanetary dust particles: Geochimica et Cosmochimica Acta, v. 61, p. 2309-2316, doi:10.1016/S0016 -7037(97)00068-9.

Farley, K.A., Ward, P., Garrison, G., and Mukhopadhyay, S., 2005, Absence of extraterrestrial helium 3 in Permian-Triassic age sedimentary rocks: Earth and Planetary Science Letters, v. 240, p. 265-275, doi:10.1016/j .epsl.2005.09.054.

Fischer, H., Siggaard-Andersen, M.L., Ruth, U., Röthlisberger, R., and Wolff, E., 2007, Glacial/interglacial changes in mineral dust and sea salt records in polar ice cores: Sources, transport, and deposition: Reviews of Geophysics, v. 45, p. 1-26, doi:10.1029/2005RG000192.

Flynn, G.J., Keller, L.P., and Sutton, S.R., 2006, Sub-micrometer scale minor element mapping in interplanetary dust particles: A test for stratospheric contamination, in 35th Lunar and Planetary Science Conference: Houston, Texas, Lunar and Planetary Institute, abstract 1334.

French, B.M., 1998, Traces of Catastrophe: A Handbook of Shock-Metamorphic Effects in Terrestrial Materials: Houston, Texas, Lunar and Planetary Institute, $120 \mathrm{p}$.

Gabrielli, P., Barbante, C., Plane, J.M., Varga, A., Hong, S., Cozzi, G., and Boutron, C.F., 2004, Meteoric smoke fallout over the Holocene Epoch revealed by iridium and platinum in Greenland ice: Nature, v. 432, p. 1011-1014.

Gayley, R.I., and Ram, M., 1984, Observations of diatoms in Greenland ice: Art Journal, v. 23, p. 71-72.

Glass, B.P., 1990, Tektites and microtektites: Key facts and inferences: Tectonophysics, v. 171, p. 393-404, doi:10.1016/0040-1951(90)90112-L.

Harris, N.W., and Bailey, M.E., 1998, Dynamical evolution of cometary asteroids: Monthly Notices of the Royal Astronomical Society, v. 297, p. 1227-1236, doi:10.1046/j.1365-8711.1998.01683.x.

Harris, R.S., Schultz, P.H., and Bunch, T.E., 2005, Accessory phases in Argentine impact breccias: Implications for shock history, emplacement dynamics, vapor composition and target lithologies, in 36th Lunar and Planetary Science Conference: Houston, Texas, Lunar and Planetary Institute, p. 1952.

Hartung, J.B., 1993, Giordano Bruno, the June 1975 meteoroid storm, Encke, and other Taurid Complex objects: Icarus, v. 104, p. 280-290, doi:10.1006/ icar.1993.1101.

Hasegawa, I., 1980, Catalogue of ancient and naked-eye comets: Vistas in Astronomy, v. 24, p. 59-102, doi:10.1016/0083-6656(80)90005-7.

Hodge, P.W., and Wright, F.W., 1964, Studies of particles for extraterrestrial origin: 2. A comparison of microscopic spherules of meteoritic and volcanic origin: Journal of Geophysical Research, v. 69, p. 2449-2454, doi:10.1029/JZ069i012p02449.

Hodge, P.W., Wright, F.W., and Langway, C.C., Jr., 1964, Studies of particles for extraterrestrial origin: 3 . Analyses of dust particles from polar ice deposits: Journal of Geophysical Research, v. 69, p. 2919-2931, doi:10.1029/ JZ069i014p02919.

Hughes, D.W., 1998, The mass distribution of crater-producing bodies, in Grady, M.M., Hutchison, R., McCall, G.J.H., and Rothery, D.A., eds., Meteorites: Flux with Time and Impact Effects: Geological Society of London Special Publication 140, p. 31-42.

Hut, P., Alvarez, W., Elder, W.P., Hansen, T., Kauffman, E.G., Keller, G., and Weissman, P.R., 1987, Comet showers as a cause of mass extinctions: Nature, v. 329, p. 118-126.

Imoto, S., and Hasegawa, I., 1958, Historical records of meteor showers in China, Korea, and Japan: Smithsonian Contributions to Astrophysics, v. 2 , p. 131-144.

Jacobson, M.Z., 2001, Strong radiative heating due to the mixing state of black carbon in atmospheric aerosols: Nature, v. 409, p. 695-697, doi: $10.1038 / 35055518$.

Jessberger, E.K., Bohsung, J., Chakaveh, S., and Traxel, K., 1992, Chondritic interplanetary dust particles and their volatile element enrichment: Earth and Planetary Science Letters, v. 112, p. 91-99, doi:10.1016/0012 -821X(92)90009-K.

Kang, S., Mayewski, P.A., Yan, Y., Qin, D., Yao, T., and Ren, J., 2003, Dust records from three ice cores: Relationships to spring atmospheric circulation over the Northern Hemisphere: Atmospheric Environment, v. 37, p. 4823-4835, doi:10.1016/j.atmosenv.2003.08.010. 
Karner, D.B., Levine, J., Muller, R.A., Asaro, F., Ram, M., and Stolz, M.R., 2003, Extraterrestrial accretion from the GISP2 ice core: Geochimica et Cosmochimica Acta, v. 67, p. 751-763, doi:10.1016/S0016 -7037(02)01145-6.

Kellogg, D.E., and Kellogg, T.E., 1996, Diatoms in South Pole ice: Implications for eolian contamination of Sirius Group deposits: Geology, v. 24 , p. 115-118, doi:10.1130/0091-7613(1996)024<0115:DISPII $>2.3 . \mathrm{CO} ; 2$.

Kellogg, D.E., and Kellogg, T.E., 2005, Frozen in time: The diatom record in ice cores from remote drilling sites on the Antarctic ice sheets, in Rogers, S.O., and Castello, J.D., eds., Life in Ancient Ice: Princeton, New Jersey, Princeton University Press, p. 69-93.

Koeberl, C., and Shirey, S.B., 1993, Detection of a meteoritic component in Ivory Coast tektites with rhenium-osmium isotopes: Science, v. 261, p. 595-598, doi:10.1126/science.261.5121.595.

Kronk, G.W., 1984, Comets: A Descriptive Catalog: Hillside, New Jersey, Enslow Publishers, $344 \mathrm{p}$.

Krueger, F.R., and Kissel, J., 1987, The chemical composition of the dust of comet P/Halley as measured by "PUMA" on board VEGA-1: Naturwissenschaften, v. 74, p. 312-316, doi:10.1007/BF00367925.

Lal, D., and Jull, A., 2005, On the fluxes and fates of He-3 accreted by the Earth with extraterrestrial particles: Earth and Planetary Science Letters, v. 235, p. 375-390, doi:10.1016/j.eps1.2005.04.011.

Lanci, L., and Kent, D.V., 2006, Meteoric smoke fallout revealed by superparamagnetism in Greenland ice: Geophysical Research Letters, v. 33, p. L13308, doi:10.1029/2006GL026480.

Larsen, L.B., Vinther, B.M., Briffa, K.R., Melvin, T.M., Clausen, H.B., Jones, P.D., Siggard-Anderson, M.-L., Hammer, C.U., Eronen, M., Grudd, H., Gunnarson, B.E., Hantemirov, R.M., Naurzbaev, M.N., and Nicolussi, K., 2008, New ice core evidence for a volcanic cause of the A.D. 536 dust veil: Geophysical Research Letters, v. 35, p. L04708, doi:10.1029/02007GL032450.

La Violette, P.A., 1987, The cometary breakup hypothesis re-examined: Monthly Notices of the Royal Astronomical Society, v. 224, p. 945-951.

Lodders, K., 2003, Solar system abundances and condensation temperatures of the elements: The Astrophysical Journal, v. 591, p. 1220-1247, doi: $10.1086 / 375492$.

Marcantonio, F., Anderson, R., Stute, M., Kumar, N., Schlosser, P., and Mix, A., 1996, Extraterrestrial He-3 as a tracer of marine sediment transport and accumulation: Nature, v. 383, p. 705-707, doi:10.1038/383705a0.

Marcantonio, F., Higgins, S., Anderson, R., Stute, M., Schlosser, P., and Rasbury, E., 1998, Terrigenous helium in deep-sea sediments: Geochimica et Cosmochimica Acta, v. 62, p. 1535-1543, doi:10.1016/ S0016-7037(98)00091-X.

Marcantonio, F., Turekian, K.K., Higgins, S., Anderson, R.F., Stute, M., and Schlosser, P., 1999, The accretion rate of extraterrestrial $3 \mathrm{He}$ based on oceanic 230Th flux and the relation to Os isotope variation over the past 200,000 years in an Indian Ocean core: Earth and Planetary Science Letters, v. 170, p. 157-168, doi:10.1016/S0012-821X(99)00100-4.

Marty, B., 2012, The origins and concentrations of water, carbon, nitrogen and noble gases on Earth: Earth and Planetary Science Letters, v. 313, p. 56-66, doi:10.1016/j.eps1.2011.10.040.

Marty, B., Alexander, C.M.D., and Raymond, S.N., 2013, Primordial origins of Earth's carbon: Reviews in Mineralogy and Geochemistry, v. 75, p. 149181, doi:10.2138/rmg.2013.75.6.

Mayewski, P.A., Meeker, L.D., Twickler, M.S., Whitlow, S.I., Yang, Q., Lyons, W.B., and Prentice, M., 1997, Major features and forcing of high-latitude Northern Hemisphere atmospheric circulation using a 110,000-yearlong glaciochemical series: Journal of Geophysical Research, v. 102, p. 26,345-26,366, doi:10.1029/96JC03365.

McGee, D., and Mukhopadhyay, S., 2013, Extraterrestrial He in sediments: From recorder of asteroid collisions to timekeeper of global environmental changes, in Burnard, P., ed., The Noble Gases as Geochemical Tracers: Berlin, Springer-Verlag, p. 155-176.

McKay, R.M., Barrett, P.J., Harper, M.A., and Hannah, M.J., 2008, Atmospheric transport and concentration of diatoms in surficial and glacial sediments of the Allan Hills, Transantarctic Mountains: Palaeogeography, Palaeoclimatology, Palaeoecology, v. 260, p. 168-183, doi:10.1016/j .palaeo.2007.08.014

McKenzie, D., and Bickle, M.J., 1988, The volume and composition of melt generated by extension of the lithosphere: Journal of Petrology, v. 29, p. 625-679, doi:10.1093/petrology/29.3.625.
Meese, D.A., Gow, A.J., Alley, R.B., Zielinski, G.A., Grootes, P.M., Ram, M., and Bolzan, J.F., 1997, The Greenland Ice Sheet Project 2 depth-age scale: Methods and results: Journal of Geophysical Research, v. 102, p. 26,411-26,423, doi:10.1029/97JC00269.

Megner, L., Siskind, D.E., Rapp, M., and Gumbel, J., 2008, Global and temporal distribution of meteoric smoke: A two-dimensional simulation study: Journal of Geophysical Research, v. 113, p. D03202, doi:10.1029/2007JD009054.

Michael the Syrian, [ca. 1166-1199 A.D.], 1901, Michael the Syrian Chronicle (translated to French by Chabot, J.-B.): Paris, Belles-Lettres.

Misawa, K., Kohno, M., Tomiyama, T., Noguchi, T., Nakamura, T., Nagao, K., and Nishiizumi, K., 2010, Two extraterrestrial dust horizons found in the Dome Fuji ice core, East Antarctica: Earth and Planetary Science Letters, v. 289, p. 287-297, doi:10.1016/j.eps1.2009.11.016.

Moore, C.H., and Wade, W.J., 2013, Carbonate diagenesis: Introduction and tools, in Carbonate Reservoirs-Porosity and Diagenesis in a Sequence Stratigraphic Framework: Amsterdam, Elsevier, Developments in Sedimentology, v. 67, p. 67-89.

Morse, J.W., Arvidson, R.S., and Lüttge, A., 2007, Calcium carbonate formation and dissolution: Chemical Reviews, v. 107, p. 342-381, doi:10.1021/ cr050358j

Mukhopadhyay, S., and Farley, K.A., 2006, New insights into the carrier phase(s) of extraterrestrial $3 \mathrm{He}$ in geologically old sediments: Geochimica et Cosmochimica Acta, v. 70, p. 5061-5073, doi:10.1016/j .gca.2006.06.1566.

O'Brien, S.R., Mayewski, P.A., Meeker, L.D., Meese, D.A., Twickler, M.S., and Wicklow, S.I., 1995, Complexity of Holocene climate as reconstructed from a Greenland ice core: Science, v. 270, p. 1962-1964, doi:10.1126/ science.270.5244.1962.

Parsons, B., and Sclater, J.G., 1977, An analysis of the variation of ocean floor bathymetry and heat flow with age: Journal of Geophysical Research, v. 82, p. 803-827, doi:10.1029/JB082i005p00803.

Pepin, R.O., Becker, R.H., and Rider, P.E., 1995, Xenon and krypton isotopes in extraterrestrial regolith soils and in the solar wind: Geochimica et Cosmochimica Acta, v. 59, p. 4997-5022, doi:10.1016/0016-7037(96)80916-1.

Peucker-Ehrenbrink, B., and Ravizza, G., 2000, The effects of sampling artifacts on cosmic dust flux estimates: A reevaluation of nonvolatile tracers (Os, Ir): Geochimica et Cosmochimica Acta, v. 64, p. 1965-1970, doi:10.1016/S0016-7037(99)00429-9.

Ramanathan, V., and Carmichael, G., 2008, Global and regional climate changes due to black carbon: Nature Geoscience, v. 1, p. 221-227, doi:10.1038/ ngeo156.

Reid, R.P., and Macintyre, I.G., 1998, Carbonate recrystallization in shallow marine environments: A widespread diagenetic process forming micritized grains: Journal of Sedimentary Research, v. 68, p. 928-946, doi:10.2110/jsr.68.928.

Rietmeijer, F.J., 1988, Sulfides and oxides in comets: The Astrophysical Journal, v. 331, p. L137, doi:10.1086/185253.

Rietmeijer, F.J., 1989, Tin in a chondritic interplanetary dust particle: Meteoritics, v. 24, p. 43-47, doi:10.1111/j.1945-5100.1989.tb00940.x.

Rietmeijer, F.J., 1993, The bromine content of micrometeorites: Arguments for stratospheric contamination: Journal of Geophysical Research-Planets, v. 98, p. 7409-7414, doi:10.1029/93JE00118.

Rietmeijer, F.J., 1995, Post-entry and volcanic contaminant abundances of zinc, copper, selenium, germanium and gallium in stratospheric micrometeorites: Meteoritics, v. 30, p. 33-41, doi:10.1111/j.1945-5100.1995 .tb01209.x.

Rigby, E., Symonds, M., and Ward-Thompson, D., 2004, A comet impact in AD536?: Astronomy and Geophysics, v. 45, p. 1.23-21.26.

Roberts, D. L., and Jones, A., 2004, Climate sensitivity to black carbon aerosol from fossil fuel combustion: Journal of Geophysical ResearchAtmospheres (1984-2012), v. 109, D16202, doi:10.1029/2004JD004676.

Schulze, H., Kissel, J., and Jessberger, E.K., 1997, Chemistry and mineralogy of Comet Halley's dust, in Pendleton, Y.J., and Tielens, R.G.G.M., eds., From Stardust to Planetesimals, Volume 122: Santa Clara, California, Astronomical Society of the Pacific, p. 397-414.

Sclar, C.B., Bauer, J.F., Pickart, S.J., and Alperin, H.A., 1973, Shock effects in experimentally shocked terrestrial ilmenite, lunar ilmenite of rock fragments in 1-10 mm fines $(10085,19)$ and lunar rock 60015, 127: Geochimica et Cosmochimca Acta, v. 1, supplement 4, p. 841-859.

Stothers, R.B., 1984, Mystery cloud of AD536: Nature, v. 307, p. 344-345, doi:10.1038/307344a0. 
Taylor, S., Lever, J.H., and Harvey, R.P., 1998, Accretion rate of cosmic spherules measured at the South Pole: Nature, v. 392, p. 899-903, doi: $10.1038 / 31894$.

Taylor, S., Lever, J.H., and Harvey, R.P., 2000, Numbers, types, and compositions of an unbiased collection of cosmic spherules: Meteoritics \& Planetary Science, v. 35, p. 651-666, doi:10.1111/j.1945-5100.2000.tb01450.x.

Thomas, K.L., Blanford, G.E., Keller, L.P., Klöck, W., and McKay, D.S., 1993, Carbon abundance and silicate mineralogy of anhydrous interplanetary dust particles: Geochimica et Cosmochimica Acta, v. 57, p. 1551-1566, doi:10.1016/0016-7037(93)90012-L.

Valsecchi, G.B., Morbidelli, A., Gonczi, R., Farinella, P., Froeschle, C., and Froeschle, C., 1995, The dynamics of objects in orbits resembling that of P/Encke: Icarus, v. 118, p. 169-180, doi:10.1006/icar.1995.1183.

Van Eaton, A.R., Harper, M.A., and Wilson, C.J., 2013, High-flying diatoms: Widespread dispersal of microorganisms in an explosive volcanic eruption: Geology, v. 41, p. 1187-1190, doi:10.1130/G34829.1.

Wark, D.A., 1986, Evidence for successive episodes of condensation at high temperature in a part of the solar nebula: Earth and Planetary Science Letters, v. 77, p. 129-148, doi:10.1016/0012-821X(86)90155-X.

Winckler, G., and Fischer, H., 2006, 30,000 years of cosmic dust in Antarctic ice: Science, v. 313, p. 491, doi:10.1126/science.1127469.
Wu, Y., Sharma, M., LeCompte, M.A., Demitroff, M.N., and Landis, J.D., 2013, Origin and provenance of spherules and magnetic grains at the Younger Dryas boundary: Proceedings of the National Academy of Sciences of the United States of America, v. 110, p. E3557-E3566, doi:10.1073/ pnas. 1304059110 .

Yada, T., Nakamura, T., Takaoka, N., Noguchi, T., Terada, K., Yano, H., and Kojima, H., 2004, The global accretion rate of extraterrestrial materials in the last glacial period estimated from the abundance of micrometeorites in Antarctic glacier ice: Earth, Planets, and Space, v. 56, p. 67-80.

Yang, H.J., Park, C., and Park, M.G., 2005, Analysis of historical meteor and meteor shower records: Korea, China, and Japan: Icarus, v. 175, p. 215225, doi:10.1016/j.icarus.2004.10.007.

Zdanowicz, C.M., Zielinski, G.A., Wake, C.P., Fisher, D.A., and Koerner, R.M., 2000, A Holocene record of atmospheric dust deposition on the Penny Ice Cap, Baffin Island, Canada: Quaternary Research, v. 53, p. 62-69, doi:10.1006/qres.1999.2091.

Manuscript Accepted by the Society 31 January 2014 
